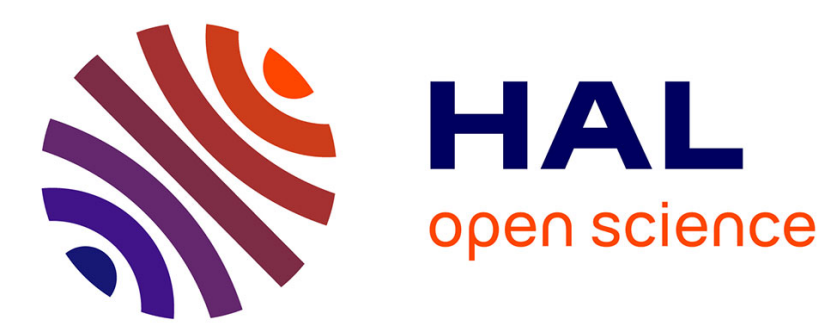

\title{
Does flood experience modify risk preferences? Evidence from an artefactual field experiment in Vietnam
}

Arnaud Reynaud, Cécile Aubert

\section{To cite this version:}

Arnaud Reynaud, Cécile Aubert. Does flood experience modify risk preferences? Evidence from an artefactual field experiment in Vietnam. Geneva Risk and Insurance Review, 2020, 45 (1), pp.36-74. 10.1057/s10713-019-00044-w . hal-03050685

\section{HAL Id: hal-03050685 \\ https://hal.science/hal-03050685}

Submitted on 18 Jan 2021

HAL is a multi-disciplinary open access archive for the deposit and dissemination of scientific research documents, whether they are published or not. The documents may come from teaching and research institutions in France or abroad, or from public or private research centers.
L'archive ouverte pluridisciplinaire HAL, est destinée au dépôt et à la diffusion de documents scientifiques de niveau recherche, publiés ou non, émanant des établissements d'enseignement et de recherche français ou étrangers, des laboratoires publics ou privés. 


\title{
Does flood experience modify risk preferences? Evidence from an artefactual field experiment in Vietnam
}

\author{
Arnaud Reynaud $^{1}$ (D) Cécile Aubert $^{2}$ \\ Received: 23 March 2018 / Accepted: 5 November 2019 \\ (c) International Association for the Study of Insurance Economics 2019
}

\begin{abstract}
We conducted an artefactual field experiment in Vietnam to investigate whether and how experiencing a natural disaster affects individual attitudes toward risks. Using experimental and real household data, we show that households in villages affected by a flood in recent years exhibit more risk aversion, compared with individuals living in similar but unaffected villages. Interestingly, this result holds for the loss domain, but not the gain domain. In line with Prospect Theory, Vietnamese households distort probabilities. The distortion is related to aid received and social networks participation, but is unrelated to flood experience.
\end{abstract}

Keywords Risk preferences $\cdot$ Non-expected utility $\cdot$ Flood $\cdot$ Vietnam $\cdot$ Field experiment

JEL CODES D9 $\cdot$ Q54 $\cdot$ Q56 $\cdot$ C93

\section{Introduction}

Most real-life choices entail risk or uncertainty and are therefore partly determined by the risk preferences of the decision-makers. Recent empirical research has shown that the way individuals make choices under risk may change when they experience a shock such as a natural disaster (Cameron and Shah 2015; Said et al. 2015; Cassar et al. 2017). This is an important issue given the increasing prevalence of

Electronic supplementary material The online version of this article (https://doi.org/10.1057/s1071 3-019-00044-w) contains supplementary material, which is available to authorized users.

Arnaud Reynaud

arnaud.reynaud@inra.fr

Cécile Aubert

cecile.aubert@u-bordeaux.fr

1 Toulouse School of Economics, INRA, University of Toulouse Capitole, Toulouse, France

2 University of Bordeaux, GREThA, and Toulouse School of Economics, Bordeaux, France

Published online: 11 December 2019 
environmental shocks, especially in developing countries. In Vietnam, floods are frequent and socially costly accounting for $49 \%$ of total economic losses due to natural disasters (WorldBank 2005). Vietnamese households are especially hurt by floods, as they have very limited access to insurance mechanisms. Aside from their obvious economic effects, floods can have overlooked long-lasting consequences if they impact decisions under risk. Climate change is expected to increase the intensity and frequency of floods (Hirabayashi et al. 2013). Market insurance for flood is largely not available and therefore cannot be a substitute for self-insurance (Ehrlich and Becker 1972). In this context, self-protection and self-insurance strategies are both especially important and dependent on risk attitudes (Dionne and Eeckhoudt 1985). One could thus design more efficient prevention, protection and emergency policies if one had more accurate information on how individuals make decisions after experiencing floods.

The object of this paper is to assess the precise, medium- to long-term, impact on risk preferences of experiencing a flood in the past 5 years in Vietnam. To do so, we collected incentivized experimental and survey data, which is detailed enough to study potential mediating factors. To obtain a more detailed picture of how decisions under risk may change, we allow for Prospect Theory preferences: choices are made in the gain and the loss domains and subjective weighting of probabilities is considered. We account for different measures of flood experience as well as for expectations about future flooding, social involvement and formal aid, that may all mediate the impact of a disaster on risk preferences.

\subsection{Disasters and preferences}

The impact of experiencing natural disasters (floods, earthquakes, volcanic eruptions) on risk attitudes has been the object of recent empirical research (Eckel et al. 2009; Andrabi and Das 2010; Li et al. 2011a; Ali Bchir and Willinger 2013; Page et al. 2014; Cameron and Shah 2015; Said et al. 2015; Cassar et al. 2017). Impacts on time preferences (Li et al. 2011; Ali Bchir and Willinger 2013; Callen 2015; Cassar et al. 2017) and on social preferences (Cassar et al. 2017; Becchetti et al. 2017) have also been explored. Though causality is difficult to establish, several of these studies suggest that exposed individuals have their preferences lastingly changed. The literature is however not fully conclusive as we discuss in the next section.

Existing studies do not distinguish risk taking in the gain and the loss domains, except for a study in psychology ( $\mathrm{Li}$ et al. 2011a). This is, however, an especially meaningful distinction: economic studies show that individuals tend to be averse to risk for gains but not for losses (Schoemaker 1990; Tversky and Kahneman 1992; Abdellaoui 2000; Abdellaoui et al. 2008) so that shocks may potentially have a different impact for gains and losses. Besides the neuroscience literature has shown that decision-making under risk in the gain and the loss domains rely on different neural structures associated to emotions (Levin et al. 2012; Weller et al. 2007). The impact of a salient and emotional event such as a flood may therefore be different for losses, which activate stronger emotional reactions. 


\subsection{Identifying the mechanisms at play}

A natural disaster may either actually change risk preferences, or only change attitudes. Preferences are fundamental features that refer to an underlying taste of the individual, while attitudes are derived from the choices made by the individual (that depend on both taste and circumstances), Weber and Ancker (2010). ${ }^{1}$

Preferences may actually change if the way the cognitive and the emotional systems are involved in decision-making are modified by the environmental shock (Loewenstein et al. 2001). After a trauma, individuals may put a higher weight on emotions (Eckel et al. 2009).

However, behaviors may change after a disaster (in the absence of a preference change) due to a changed perception of the background risk or to wealth effects. Background risk refers to some unavoidable risk that affects an individual who considers a decision that involves another, independent, risk (Kimball 1993). The experimental tasks that are used to elicit risk preferences, bear on monetary risks given an (unknown to the experimenter) environment with which the subject interacts. An apparent change in risk preferences may actually be due to a change in the individual's perception of the other risks present in his environment. Changes in risk perception after a natural disaster have been highly documented, especially in the context of floods (Bubeck et al. 2012; Ho et al. 2008; Knuth et al. 2014). A natural disaster may constitute a shock that contains new information, causing a rational update in estimates of background risk (Cameron and Shah 2015). Depending on the structure of individuals preferences, the change in background risk may then lead to more or less cautious behaviors (Gollier and Pratt 1996; Quiggin 2003; Beaud and Willinger 2015). Last, experiencing a flood could change wealth. If a respondent is poorer or if he expects a higher background risk (e.g., another flood) after being flooded, then his choices may change even if his underlying preferences do not.

While one would need extremely detailed data to definitely solve the identification problem described above, our data will allow us to get more insight about the different possible effects at play.

\subsection{Our approach and methods}

Beyond asserting the existence, or absence, of an impact of disaster on risk preferences, several points deserve more analysis and are the object of this article: Are monetary odds weighted differently after the experience of the disaster? If there is an impact of disaster experience, is it of the same magnitude for risks implying gains than for risks implying losses? And are preferences truly modified, or is the impact on attitudes towards risks solely due to changing risk perceptions about natural risks or to wealth effects?

\footnotetext{
1 The question of whether preferences or only attitudes are changed also refers to the notion of conditional and unconditional preference stability. In our context, the environment of an individual is much changed after a disaster so that we cannot discuss unconditional stability. But we do attempt to identify more precisely some potential mediators of a change in choices.
} 
To address the various aspects mentioned, we gather detailed data from representative, randomly selected households located in a Vietnamese province affected by severe flooding. Our data includes incentivized lotteries, some in the gain domain, others in the loss domain, which are standard risk games using real money. We then combine our experimental measurement of risk attitude (decontextualized lottery choices) with real data on flooding experience. ${ }^{2}$ Our detailed data allows to account for different measures of flood experience and to control for a range of factors that include involvement in social networks and aid received from various sources.

A novelty of our approach is to allow for a non-expected utility representation-a prospect theory (PT) framework. Most existing empirical studies constrain preferences to follow the expected utility (EU) model. Under the PT framework, we can provide a more precise description of the impact of experiencing a disaster on risk preferences, isolating different dimensions (gains, losses, probability distortion). This impact is not restricted to be the same for gains and losses, in particular.

In addition, our measures of both personal and indirect experience, and of perceived flood risk, help provide more insight into the sources of any preference change. Our data allows distinguishing personal experience of a flood, expectations about future damages (which measure an individual perception of the background risk) and village-level experience (which is another, objective and history-based, measure of background risk). Our results point to a very different impact of these measures on risk taking. Interestingly, we can measure whether personal experience has an impact once either of the two measures of background risk are taken into account. These results are important for adequately designing public aid, prevention and public or private insurance contracts.

The remainder of the paper is organized as follows. Section 2 provides some more information on floods in Vietnam and on the existing literature about disasters and preferences. Section 3 describes the experimental design used for eliciting individual risk preferences. We discuss our data sources in Sect. 4, and our identification strategy and results in Sect. 5. Section 6 presents robustness checks and Sect. 7 concludes.

\section{Context and literature}

\subsection{Flood risk in Vietnam}

Vietnam ranks fourth in the World, after India, Bangladesh and China, in terms of population affected by flood each year. ${ }^{3}$ Vietnam indeed receives heavy rain during the monsoon season (from 1200 to $3000 \mathrm{~mm}$, nearly $90 \%$ of which occur in summer). In addition, 6 to 8 typhoons hit the Vietnamese coasts every year on average. The combination of typhoon and monsoon seasons defines the flooding season

\footnotetext{
2 Other works combining experimental measures of risk preferences with real decisions include Azevedo et al. (2003), Brunette et al. (2017).

${ }^{3}$ See https://www.wri.org/resources/data-sets/aqueduct-global-flood-risk-country-rankings.
} 
which usually starts in July and ends in November. It is particularly costly since $70 \%$ of the population lives in coastal areas, usually only a few meters above sea level (Mai et al. 2009).

Flood management policies in Vietnam have been historically dominated by structural measures such as building dikes or dams, even if a recent move towards non-structural approaches, such as population education and preparedness, warning systems and insurance mechanisms has been observed (Pilarczyk and Nuoi 2005).

The Vietnamese market for life and non-life insurance only represented $1.5 \%$ of GDP in 2011 (compared to 5.8\% on average in Asia) (SwissRe 2012). Coverage for natural catastrophe perils is usually included in property insurance policies, but subscriptions to property insurance remain very limited in urban areas, and almost nonexistent in rural areas (WorldBank 2010). Catastrophic agricultural insurance is also extremely uncommon. According to the Vietnamese Finance Ministry, only 1\% of farmers are currently insured against damage to crops. Government disaster relief payments are often the only source of compensation received by farmers after major floods or storms (WorldBank 2010).

\subsection{Risk preferences and natural disasters: empirical evidence}

There is a now a large empirical literature looking at how preferences are impacted by extreme events such as natural disasters. It is however not fully conclusive.

Some studies document more risk seeking in the gain domain after experiencing a natural disaster. These include Eckel et al. (2009) for evacuees from hurricane Katrina, in its immediate aftermath; Ali Bchir and Willinger (2013) for poor Peruvian households exposed to a volcanic threat; Said et al. (2015) for flooded households in Pakistan; and Page et al. (2014) for flooded households in Australia.

However, other studies document more risk-averse behaviors following a disaster. They include Andrabi and Das (2010) for Pakistanese living close to an earthquake fault line; Cameron and Shah (2015) for Indonesian people after floods or earthquakes; Cassar et al. (2017) for Thai individuals affected by the 2004 tsunami; and Samphantharak and Chantarat (2015) for Thai exposed to the 2011 mega flood.

Lastly, a few studies report no significant relationship between risk attitudes and disaster experience. Callen (2015) documents no change in risk preferences for workers in Sri Lanka having experienced the 2004 Asian tsunami. Voors et al. (2012) report that shocks such as drought and excess rainfall do not significantly impact risk preferences in Burundi, while exposure to violent conflict does.

As discussed in Chuang and Schechter (2015), the lack of consistency in these results suggests that there may be issues involved in the experience of a natural disaster that have not been considered yet in the existing studies, or that experimental choices are too noisy.

To get a better understanding of the complex relationship between risk preferences and experiencing a natural disaster, we collect detailed data and follow two directions. First, we consider risk preferences in the gain domain but also in the loss domain. Second, we allow for preferences following prospect theory. Both directions appear especially relevant given the existing literature on preferences under risk. 


\subsection{Separating gains and losses}

To our best knowledge, Li et al. (2011a) is the only study (in psychology) having considered a differentiated impact in the loss and in the gain domain of having experienced natural disasters (a heavy snow-hit and a major earthquake in China in 2008). Their results suggest that people tend to give more weight to low probabilities after a disaster, preferring a sure loss (less risk seeking in loss domain) but a probable gain (less risk aversion in gain domain). These results were, however, obtained with hypothetical choices, without any structural estimation of risk preferences. Separating the loss and gain domains in the context of a shock may matter since decision-making under risk in the gain and the loss domains involves different psychological processes, and relies on different neural structures (Levin et al. 2012; Weller et al. 2007).

A large literature in experimental economics (Schoemaker 1990; Tversky and Kahneman 1992; Abdellaoui 2000; Abdellaoui et al. 2008) also finds support for stronger risk aversion in the gain than in the loss domain. Under cumulative prospect theory (Tversky and Kahneman 1992) the value function is concave for gains but convex for losses, for moderate probabilities. This is known as the "reflection effect". It is in line with previous results from Schoemaker (1990) and is confirmed by various studies, including Abdellaoui (2000) with a parameter-free elicitation procedure, or Levin and Hart (2003) for children (Tversky and Kahneman 1992) find that $88 \%$ of subjects are risk-averse for gains and $87 \%$ of subjects risk seeking for losses (Baucells and Villasís 2010) have similar results: $72 \%$ of the subjects have preferences concave for gains and convex for losses (with 24\% risk-averse for both gains and losses and $4 \%$ rather risk seeking). To the best of our knowledge no study has assessed whether shocks may affect differently preferences for gains and preferences for losses. This is a novelty of our analysis.

A second, and related, novelty is that we explicitly allow for preferences that follow Prospect Theory. Although some of the papers examining the impact of shocks on preferences indicate that their findings are consistent with PT (Li et al. 2011a; Page et al. 2014; Said et al. 2015) most of them use EU models for eliciting risk preferences with lottery games. Yet since the works of Allais and Ellsberg in the 1950s, psychologists and economists have provided substantial evidence that individuals do not necessarily behave according to the EU framework. One may argue that differences in decision-making observed after a natural disaster may not be imputed solely to a different curvature of the utility function but also to other modifications of individual preferences such as distorted probability weighting. Our experimental design will allow us to assess these potential effects of natural disasters on individual preferences using a non-expected utility framework.

\section{Experimental design}

\subsection{Risk preference specification}

As argued above, flood experience may have a different impact on risk preferences in these two domains. To address this possibility, we assume that respondents's 
preferences follow the (cumulative) PT framework (Kahneman and Tversky 1979; Tversky and Kahneman 1992).

Under PT, individuals have sophisticated preferences that encompass reference dependence and probability weighting. Outcomes are considered as either gains or losses, with respect to a labile reference point, and individuals behave differently for gains and losses. Moreover, preferences are non-linear in probabilities, to account for the fact that individuals distort probabilities into decision weights.

In PT, risk behavior arises from the interplay of utility curvature, probability weighting, and reference dependence:

$$
u(y) \equiv \begin{cases}y^{\alpha} & \text { if } y>0 \\ 0 & \text { if } y=0 \\ -(-y)^{\beta} & \text { if } y<0\end{cases}
$$

where $\alpha$ and $\beta$ are parameters representing the curvature of the utility function, respectively, for the gain and the loss domains. The existing literature suggests that utility is concave for gains and convex for losses, and steeper for losses than for gains. Due to empirical considerations, we do not include a parameter of loss aversion. ${ }^{4}$

Under PT, the objective probabilities are distorted by a probability weighting function, $\omega(.) .^{5}$ The probability weighting function is strictly increasing from the unit interval onto itself and satisfies $\omega(0)=0$ and $\omega(1)=1$. Its specification has been widely discussed. We follow Gonzalez and Wu (1999) by assuming a linear relationship between logs, which yields:

$$
\omega(p) \equiv \frac{p^{\gamma}}{p^{\gamma}+(1-p)^{\gamma}}
$$

where $\gamma$ is the parameter controlling the curvature of the probability weighting function.

Decision weights defined over the cumulative probability distributions were introduced by Tversky and Kahneman (1992). The value of the prospect $\left(y_{1}, p ; y_{2}\right)$ is as follows:

$$
U\left(y_{1}, p ; y_{2}\right)=\left\{\begin{array}{l}
\omega(p) \cdot u\left(y_{1}\right)+[1-\omega(p)] \cdot u\left(y_{2}\right) \text { if } y_{1} \geq y_{2} \geq 0 \text { or } y_{1} \leq y_{2} \leq 0 \\
\omega(p) \cdot u\left(y_{1}\right)+\omega(1-p) \cdot u\left(y_{2}\right) \text { if } y_{1}<0<y_{2} .
\end{array}\right.
$$

\footnotetext{
${ }^{4}$ In Tversky and Kahneman (1992), a loss aversion parameter is specified. The use of our simplified form has been dictated by empirical considerations. Our pilot experiment has indeed revealed that Vietnamese households had some difficulties manipulating lotteries involving both gains and losses, which are required for identifying loss aversion. Bruhin et al. (2010) also use a similar sign-dependent power function arguing that it is the best compromise between parsimony and goodness of fit in the context of PT.

5 Tversky and Kahneman (1992) consider different probability weighting functions, one for the gain domain and the other for the loss domain. However, in most empirical applications they are the same (Abdellaoui et al. 2016).
} 
With the above functional forms, risk preferences are characterized by three parameters: $\alpha$ and $\beta$ represent the curvature of the utility function in the gain and in the loss domains, respectively, and $\gamma$ reflects the curvature of the probability weighting function.

EU is here a special case where $\alpha=\beta$ and $\gamma=1$. Because our estimated parameters will differ from these, we find an overall support for CPT. Note that Tanaka et al. (2010) find that CPT describes their data better than EU on a sample of rural Vietnamese households, similar to our own sample. In addition, our specification implies Decreasing Absolute Risk Aversion (DARA) and Constant Relative Risk Aversion (CRRA). ${ }^{6}$ These theoretical assumptions will indeed be met by our estimates, as will be discussed.

\subsection{Risk tasks}

We use incentivized lottery tasks to measure the risk preferences of households, with an Ordered Lottery Selection (OLS) procedure. Our approach is based on the experiment initially proposed in Eckel and Grossman (2002) (hereafter EG). The EG task has been used by, among others, Engle-Warnick et al. (2009), Dave et al. (2010), Castillo et al. (2010), Eckel et al. (2009) and Cameron and Shah (2015). The task is very similar to the famous one initially proposed by Binswanger (1980).

The EG task presents respondents with a limited set of gambles, lotteries with a $50 / 50$ chance of winning a low prize or a high prize; they are then asked to choose the lottery they prefer. The lotteries are designed to be increasing in expected payoff and risk (standard deviation). An important advantage of this design is that it is simple enough to be easily understood by subjects outside the usual convenient sample of university students. This is very important in our context since many of our participants have received little or no education.

We extend the EG basic framework in several directions. First, we do not restrict individuals to play 50/50 chance lotteries: We use two additional tasks involving $40 / 60$ and 20/80 chance of winning a low or a high prize. By varying probabilities, we can assess if subjects use non-linear probability weights. Second, we introduce the possibility of making losses to elicit decisions both in the gain and in the loss domains. This is particularly important in our context since we expect households who have experienced a flood to have different risk-taking behaviors in these two domains. Lastly, we increase the number of lotteries in the gain domain from 5 to 9 to measure risk preferences in a more precise way. ${ }^{7}$

Table 1 presents the five risk tasks completed by each individual. Tasks 1-3 involve only gains whereas tasks 4 and 5 involve only losses. The expected payoffs and standard deviation of payoffs decrease with the lottery number, so that a

\footnotetext{
${ }^{6}$ With our specification, the Arrow-Pratt absolute risk aversion coefficients for income $y$ are $(1-\alpha) / y$ in the gain domain and $(1-\beta) / y$ in the loss domain, and are thus decreasing in $y$. The relative risk aversion coefficients are equal to $1-\alpha$ and $1-\beta$ and are thus constant.

7 Because we are primarily interested in the impact of flood experience on preferences, this asymmetry in the number of gambles should have a very limited impact on our analysis.
} 
risk-averse individual should select a lottery in the bottom of each task. The least risky, or 'safest' lotteries are lotteries 8 and 9 for tasks $1-3$, and lottery 5 for tasks 4 and 5.

\subsection{Risk preference elicitation}

We use lottery choices to generate individual-specific intervals for each of the three parameters $(\alpha, \beta, \gamma)$ following the elicitation approach initially proposed by Tanaka et al. (2010) and more recently implemented by Liu (2013). ${ }^{8}$

In Table 1, each lottery in tasks $1-5$ can be written as $\left(X_{H, k}, X_{L, k} ; p_{H, k}\right)$, where $X_{H, k}$ and $X_{L, k}$ are the high and the low payoffs in lottery $k$, and $p_{H, k}$ is the probability of the high payoff. The utility derived from lottery $k$ is $\omega\left(p_{H, k}\right) \cdot X_{H, k}^{\alpha}+\left(1-\omega\left(p_{H, k}\right)\right) \cdot X_{L, k}^{\alpha}$. If lottery $k$ is chosen, it means that it is preferred to lotteries $k-1$ and $k+1$, which translates into a system of equations that allows us to identify the parameters. Note that, in all five tasks, for subjects preferring the first (respectively the last) lottery, one can only infer an upper (respectively a lower) bound on the parameter to be estimated.

Task 1 involves only gains and equiprobabilities $\left(p_{H, k}=0.5\right)$. Using the fact that $\omega(0.5)=0.5$ it is easy to show that individual decisions depend only on $\alpha$, the curvature of the utility function in the gain domain. If lottery $k$ is chosen, it is preferred to lotteries $k-1$ and $k+1$, which translates into:

$$
\begin{gathered}
X_{H, k}^{\alpha}+X_{L, k}^{\alpha}>X_{H, k-1}^{\alpha}+X_{L, k-1}^{\alpha} \\
X_{H, k}^{\alpha}+X_{L, k}^{\alpha}>X_{H, k+1}^{\alpha}+X_{L, k+1}^{\alpha} .
\end{gathered}
$$

This system of equations determines an interval $\left[\underline{\alpha}_{k}, \bar{\alpha}_{k}\right]$ for each preferred lottery $k$. The same logic will be applied to the other parameters to be estimated.

Tasks 4 and 5 only involve losses and equiprobabilities $\left(p_{H, k}=0.5\right)$. Again, since $\omega(0.5)=0.5$ it is easy to show that individual decisions thus only depend on $\beta$, the curvature of the utility function in the loss domain. Applying the same logic as above to lottery $k, k=1, \ldots, 5$, one obtains:

$$
\begin{aligned}
& -\left(-X_{H, k}\right)^{\beta}-\left(-X_{L, k}\right)^{\beta}>-\left(-X_{H, k-1}\right)^{\beta}-\left(-X_{L, k-1}\right)^{\beta} \\
& -\left(-X_{H, k}\right)^{\beta}-\left(-X_{L, k}\right)^{\beta}>-\left(-X_{H, k+1}\right)^{\beta}-\left(-X_{L, k+1}\right)^{\beta} .
\end{aligned}
$$

This system of equations determines an interval $\left[\underline{\beta}_{k}, \bar{\beta}_{k}\right]$ for each preferred lottery $k$. For subjects preferring the first or the last lottery, only an upper or a lower bound for

\footnotetext{
${ }^{8}$ An alternative approach would have been to estimate the risk preference parameter using maximum likelihood, following the approach proposed by Harrison and Rutström (2008). As a robustness check, we have estimated the three parameters $(\alpha, \beta, \gamma)$ using this approach. Estimates are quite consistent with the individual-specific mid-point intervals obtained using the Tanaka et al. (2010) approach, and are available from authors upon request.
} 
Table 1 Definition of risk tasks

\begin{tabular}{|c|c|c|c|c|c|c|}
\hline Task number & Domain & $\begin{array}{l}\text { Lottery } \\
\text { number }\end{array}$ & Payoff (high) & Prob. (high) & Payoff (low) & Prob. (low) \\
\hline 1 & Gain & 1 & 94,200 & 0.5 & 3600 & 0.5 \\
\hline 1 & Gain & 2 & 93,600 & 0.5 & 3800 & 0.5 \\
\hline 1 & Gain & 3 & 90,000 & 0.5 & 6000 & 0.5 \\
\hline 1 & Gain & 4 & 85,200 & 0.5 & 9000 & 0.5 \\
\hline 1 & Gain & 5 & 81,000 & 0.5 & 10,800 & 0.5 \\
\hline 1 & Gain & 6 & 73,200 & 0.5 & 13,200 & 0.5 \\
\hline 1 & Gain & 7 & 66,500 & 0.5 & 15,000 & 0.5 \\
\hline 1 & Gain & 8 & 63,000 & 0.5 & 15,600 & 0.5 \\
\hline 1 & Gain & 9 & 59,400 & 0.5 & 16,200 & 0.5 \\
\hline 2 & Gain & 1 & 87,500 & 0.6 & 10,000 & 0.4 \\
\hline 2 & Gain & 2 & 82,500 & 0.6 & 15,000 & 0.4 \\
\hline 2 & Gain & 3 & 77,500 & 0.6 & 20,000 & 0.4 \\
\hline 2 & Gain & 4 & 74,000 & 0.6 & 23,000 & 0.4 \\
\hline 2 & Gain & 5 & 71,000 & 0.6 & 25,000 & 0.4 \\
\hline 2 & Gain & 6 & 67,500 & 0.6 & 27,500 & 0.4 \\
\hline 2 & Gain & 7 & 64,000 & 0.6 & 30,000 & 0.4 \\
\hline 2 & Gain & 8 & 61,000 & 0.6 & 32,000 & 0.4 \\
\hline 2 & Gain & 9 & 58,000 & 0.6 & 34,000 & 0.4 \\
\hline 3 & Gain & 1 & 60,000 & 0.8 & 7000 & 0.2 \\
\hline 3 & Gain & 2 & 59,000 & 0.8 & 10,000 & 0.2 \\
\hline 3 & Gain & 3 & 58,000 & 0.8 & 13,000 & 0.2 \\
\hline 3 & Gain & 4 & 57,000 & 0.8 & 15,000 & 0.2 \\
\hline 3 & Gain & 5 & 56,000 & 0.8 & 16,500 & 0.2 \\
\hline 3 & Gain & 6 & 55,000 & 0.8 & 18,000 & 0.2 \\
\hline 3 & Gain & 7 & 54,000 & 0.8 & 19,500 & 0.2 \\
\hline 3 & Gain & 8 & 53,000 & 0.8 & 20,500 & 0.2 \\
\hline 3 & Gain & 9 & 52,000 & 0.8 & 21,500 & 0.2 \\
\hline 4 & Loss & 1 & -4000 & 0.5 & $-84,800$ & 0.5 \\
\hline 4 & Loss & 2 & -8000 & 0.5 & $-80,000$ & 0.5 \\
\hline 4 & Loss & 3 & -9600 & 0.5 & $-76,000$ & 0.5 \\
\hline 4 & Loss & 4 & $-10,400$ & 0.5 & $-72,000$ & 0.5 \\
\hline 4 & Loss & 5 & $-11,200$ & 0.5 & $-68,800$ & 0.5 \\
\hline 5 & Loss & 1 & $-12,500$ & 0.5 & $-50,000$ & 0.5 \\
\hline 5 & Loss & 2 & $-16,000$ & 0.5 & $-45,000$ & 0.5 \\
\hline 5 & Loss & 3 & $-19,000$ & 0.5 & $-40,000$ & 0.5 \\
\hline 5 & Loss & 4 & $-20,500$ & 0.5 & $-37,500$ & 0.5 \\
\hline 5 & Loss & 5 & $-22,000$ & 0.5 & $-35,000$ & 0.5 \\
\hline
\end{tabular}

This table describes the five experimental tasks used to elicit Prospect Theory preferences of households. All payoffs are expressed in Vietnamese Dongs (VND). The official exchange rate is 1 US\$ for VND 20,833 on April 2013 
$\beta$ can be inferred. Two intervals for the curvature of the utility function in the loss domain are elicited since we have two tasks and hence two observations per subject. This allows us to assess the stability of preferences across tasks.

Tasks 2 and 3 involve non-equiprobable lotteries in the gain domain. They allow us to identify a lower and an upper bound for the curvature of the probability weighting function (parameter $\gamma$ ), conditionally on the lottery choice in Task 1. Since:

$$
1-\omega\left(p_{H, k}\right)=1-\frac{p_{H, k}^{\gamma}}{p_{H, k}^{\gamma}+\left(1-p_{H, k}\right)^{\gamma}}=\frac{\left(1-p_{H, k}\right)^{\gamma}}{p_{H, k}^{\gamma}+\left(1-p_{H, k}\right)^{\gamma}},
$$

it implies that:

$$
U\left(X_{H, k}, X_{L, k} ; p_{H, k}\right)=\frac{1}{p_{H, k}^{\gamma}+\left(1-p_{H, k}\right)^{\gamma}} \cdot\left[\left(p_{H, k}\right)^{\gamma} \cdot X_{H, k}^{\alpha}+\left(1-p_{H, k}\right)^{\gamma} \cdot X_{L, k}^{\alpha}\right] .
$$

If lottery $k$ is the preferred one, it is preferred to lotteries $k-1$ and $k+1$. It is straightforward to show that:

$$
\begin{aligned}
& \left(p_{H, k}\right)^{\gamma} \cdot X_{H, k}^{\alpha}+\left(1-p_{H, k}\right)^{\gamma} \cdot X_{L, k}^{\alpha}>\left(p_{H, k-1}\right)^{\gamma} \cdot X_{H, k-1}^{\alpha}+\left(1-p_{H, k-1}\right)^{\gamma} \cdot X_{L, k-1}^{\alpha} \\
& \left(p_{H, k}\right)^{\gamma} \cdot X_{H, k}^{\alpha}+\left(1-p_{H, k}\right)^{\gamma} \cdot X_{L, k}^{\alpha}>\left(p_{H, k+1}\right)^{\gamma} \cdot X_{H, k+1}^{\alpha}+\left(1-p_{H, k+1}\right)^{\gamma} \cdot X_{L, k+1}^{\alpha}
\end{aligned}
$$

This system of equations determines an interval $\left[\underline{\gamma}_{k}, \bar{\gamma}_{k}\right]$ depending on the preferred lottery $k$ and conditionally on the preferred lottery in Task 1 . Here, again, two intervals for the curvature of the probability weighting function are elicited.

\section{Data}

\subsection{Questionnaire development}

After a pilot study in December 2011, the final survey (with face-to-face interviews) took place from April 4th to June 10th 2012, a period during which no flood or natural disaster was recorded in the Nghe An Province.

The survey is structured into seven sections, not all of which are used in this article. The survey also includes two choice experiments used to assess how Vietnamese households value a reduction in flood risks, and a flood insurance contract (Reynaud et al. 2013; Reynaud and Nguyen 2016; Reynaud et al. 2018). Here, we use:

(i) socio-demographic questions on household's income, housing characteristics and family structure,

(ii) questions on the respondent's experience with flooding, flood damage and evacuation due to flood threats, 
(iii) and lottery games with monetary incentives, to elicit risk preferences, using the five lottery tasks described above (see Supplementary Material 1).

\subsection{Sample}

\subsubsection{Sampling strategy}

First, 14 districts (out of 17 in the Nghe An Province) were selected based on geographical location (coastal area, plain area, mountain area). Following discussions with local representatives of the Ministry of Agriculture and Rural Development, two representative villages/communes were targeted within each district (there are 417 villages/communes in the Nghe an Province). Finally, within each village/commune 16 households were randomly selected from the village/commune listing of registered citizens. Our sample is thus made of 448 households observed in 28 villages/communes from 14 districts in the Nghe An Province.

\subsubsection{Socio-demographic characteristics in the sample}

The head of the household is 49.8-year old on average. Average household size is just above 4 and $16.7 \%$ of households have at least one child younger than three. The average household income in 2011 was VND 32.5 million per year (US\$1560)_ which is lower than the average for the Nghe An Province in 2010 (VND 48 million, or US\$2300). Farming (or fishing) is the main occupation for $79.2 \%$ of household heads. Employees represent 5.6\% of our sample and retired households, 5.1\%. Last, $30.6 \%$ of household heads have attended at least high school.

\subsection{Instructions and incentives for the risk tasks}

An important concern in risk preferences elicitation through lottery games is the extent to which subjects understand the instructions. Even though we selected simple tasks, the experiment could be complex to understand, especially with field subjects in a poor region. As many of our participants have received little or no education, we have provided all experimenters with clear and visual instructions to make it easier for illiterate subjects to understand the consequences of any decisions they made in the games. Moreover, before starting the risk tasks, we tested comprehension by asking test questions. Instructions for the experimental tasks are available in the Supplementary Material 1. To illustrate the chances of winning/losing money, we used ten balls numbered from 1 to 10 . These balls were put into a bag, and subsequently stirred.

The lottery games are incentivized, allowing respondents to earn real money based on their answers. A respondent's payoff is determined in the following way: Each respondent was given a show-up fee of VND 85000 (US\$4.08), ensuring a strictly positive payoff even in case of losses in the lottery games. We randomly selected one of the five risk tasks to be implemented with real money: Five numbered balls were 
Table 2 Household flood history and cost of flooding in the last 5 years

\begin{tabular}{|c|c|c|}
\hline Variable & Mean & SD \\
\hline \multicolumn{3}{|l|}{ Panel A: household flood history in the last 5 years } \\
\hline House flooded at least once $(0,1)$ & 0.413 & 0.493 \\
\hline Respondent evacuated at least once $(0,1)$ & 0.214 & 0.410 \\
\hline One household member injured at least once $(0,1)$ & 0.051 & 0.221 \\
\hline \multicolumn{3}{|c|}{ Panel B: cost of flooding (annual mean based on the last 5 years) } \\
\hline Flooding has represented a significant cost $(0,1)$ & 0.759 & 0.428 \\
\hline House cost (VND million) & 2.345 & 5.428 \\
\hline Agricultural cost (VND million ) & 3.000 & 5.873 \\
\hline Health cost (VND million) & 0.263 & 1.405 \\
\hline Total cost (VND million) & 5.610 & 8.859 \\
\hline House cost ( $\%$ of income $)$ & 8.624 & 20.153 \\
\hline Agricultural cost ( $\%$ of income) & 13.882 & 25.003 \\
\hline Health cost ( $\%$ of income) & 1.293 & 7.965 \\
\hline Total cost ( $\%$ of income) & 23.800 & 34.354 \\
\hline
\end{tabular}

SD is the standard deviation. Statistics reported in Panel B have been computed on a sample of 370 households

put into a bag and a random draw of a ball determined the task to be implemented. Then, ten balls were put into the bag and the preferred lottery of the household was played. The average gain obtained by respondents in the lottery game was VND 37 800 (US\$1.8) and it varied from VND -84 800 (US\$-4.1) to VND 94200 (US\$4.5) in our sample. Including the show-up fee the average monetary gain was VND 122800 (US\$5.9) which represents $4.5 \%$ of the average monthly household income. Out of the 448 households interviewed, 370 households completed the risk tasks. This subsample is not significantly different from the global sample in terms of socioeconomic characteristics (including age, income or family size) nor of household flood experience.

\subsection{Measuring household flooding experience}

We demonstrate that the cost of flooding is significant in our sample, which supports our view that floods are catastrophic events.

The Nghe An Province is exposed to flooding. Table 2 presents data about households' past experience with floods. To address the multi-dimensional nature of flooding experience (occurence, trauma, health...), three variables are used: flooding, evacuation and injuries. In our sample, $41.3 \%$ of households report that their house has been flooded at least once in the past 5 years (among them, 76.5\% have been flooded for the last time in 2011); $21.4 \%$ of respondents have been evacuated from their home due to a flood, at least once in the past 5 years (which can be considered as a traumatic event); and 5.1\% had a member of the household injured due to a flood at least once in the past 5 years. These percentages are in line with the information on flooding risk in the Nghe An Province we collected from Vietnamese public authorities. 
Concerning the cost of flooding, $75.9 \%$ of households consider that flooding has represented a significant expenditure over the previous 5 years. To assess the actual cost of flooding, we asked respondents to provide an estimate of the average annual cost of flooding for their household in the previous 5 years, distinguishing damage to their house and house contents, damage to agricultural production and damage to health (all medical expenses due to flooding for any member of the household). The cost of flooding is reported in Table 2. If we combine agricultural, house and health damage, the average annual cost of flood is VND 5.6 million per year, or $23.80 \%$ of the average annual household income.

The flood expenses reported by households could be overestimated or underestimated for strategic or psychological reasons, or simply because this data is not easily available. In the remainder of the paper, we mainly assess flood experience through the three variables mentioned above: house flooded, being evacuated, or injured due to a flood. We believe that these variables better measure the severity of the flood as perceived by the household than monetary self-reported estimates. That being said, the reported values are consistent with objective flooding risk in the Nghe An Province.

\section{Individual risk preferences and flood experience}

This section first provides evidence that flood exposure is random, by showing that our sample is balanced on retrospective variables and on fixed variables which should not be altered by flood exposure. We then present evidence of changes in risk preferences induced by a flood experience.

\subsection{Identification strategy}

Following Cameron and Shah (2015), our empirical strategy consists in regressing our risk attitude measures on the household flood experience measures, while controlling for household and geographic characteristics fixed effects. Similar identifying assumptions have been used by Page et al. (2014) for flood risks and by Callen (2015) and Cassar et al. (2017) for Tsunami risks.

A concern is that if people affected by a flood are different, on relevant characteristics, from those who have not been affected, this approach will suffer from a selection bias (Cameron and Shah 2015). More specifically, more risk-averse households may decide to live in an area where the likelihood of being flooded is lower. They may also be more likely to relocate to a safer area after having experienced a first traumatic flood. We could, therefore, observe a correlation between risk preferences and being affected by a flood. If wealthier households live in areas with a low flood risk and if risk preferences are related to income, we could also observe a positive correlation between flood experience and risk aversion that does not reflect causality.

While it is not possible to fully rule out this possibility, the characteristics of Vietnam make it less likely that flood experience and migration be strongly linked: 
First, most empirical studies suggest that internal migration in Vietnam is primarily influenced by the cost of moving, expected income differentials, disparities in the quality of public services, and demographic differences in characteristics between source and destination areas (Nguyen-Hoang and McPeak 2010). Second, although the Constitution of Vietnam guarantees freedom of movement and residence, the Household Registration System (ho khau) still creates barriers to migrations, for instance by limiting access to essential services (Dang Nguyen 2009).

To address the issue of flood-induced migration, we compare individual or household characteristics according to their flood experience using two-sample $t$ tests (see Table 3). There is a huge empirical literature which has investigated how risk preferences vary across some observable characteristics of households. The interested reader may refer to Eckel and Grossman $(2002,2008)$ for studies correlating risk preferences and gender of respondents. Dohmen et al. (2011) provides an assessment of the role of education on individual risk preferences. For income, the general consensus is that wealthier households are more likely to have a risk-seeking profile (Hopland et al. 2016). Here, income, gender, education, household size and presence of a child under 3 years, which are among the strongest and most consistent predictors of risk preferences across studies, appear not to statistically differ across samples whatever the flooding experience considered (being flooded, evacuated and injured). Households who experienced a flood in the past five years are thus not different from those who did not, with respect to the main variable of interest. We can compare the risk preferences of affected and non-affected households to determine the causal effect of experiencing a flood on risk preferences.

\subsection{Preferred lotteries and flooding experience}

Table 4 documents the percentage of respondents per preferred lottery, for each task. Results are presented for all households, for households whose house has been flooded at least once in the past 5 years, for households evacuated at least once in the past 5 years and for households injured at least once in the past 5 years. We also report results according to flooding intensity in the past 5 years, separating households reporting water elevation in their house greater than $100 \mathrm{~cm}$ at least once, and households who have been flooded more than 8 days per year.

Table 4 calls for a few comments. First, the distributions of preferred lotteries appear to often be bimodal with a particularly high proportion of respondents choosing one of the extreme lotteries. For the 'gain' tasks (tasks 1-3), between 70 and $80 \%$ of respondents choose an interior lottery (lotteries 2-8). Depending on the task, between 15.7 and $20.8 \%$ of respondents prefer the riskiest lottery (lottery 1) whereas between 3.0 and $11.4 \%$ prefer the safest one (lottery 9). This indicates a high heterogeneity of risk preferences in the gain domain which can also be observed in the loss domain (tasks 4 and 5).

Flood experience appears to have a significant impact on the preferred lottery, both in the gain and in the loss domains. For instance in task 1 (gain domain), 24.1\% of households having experienced at least one house flooding over the last five years 


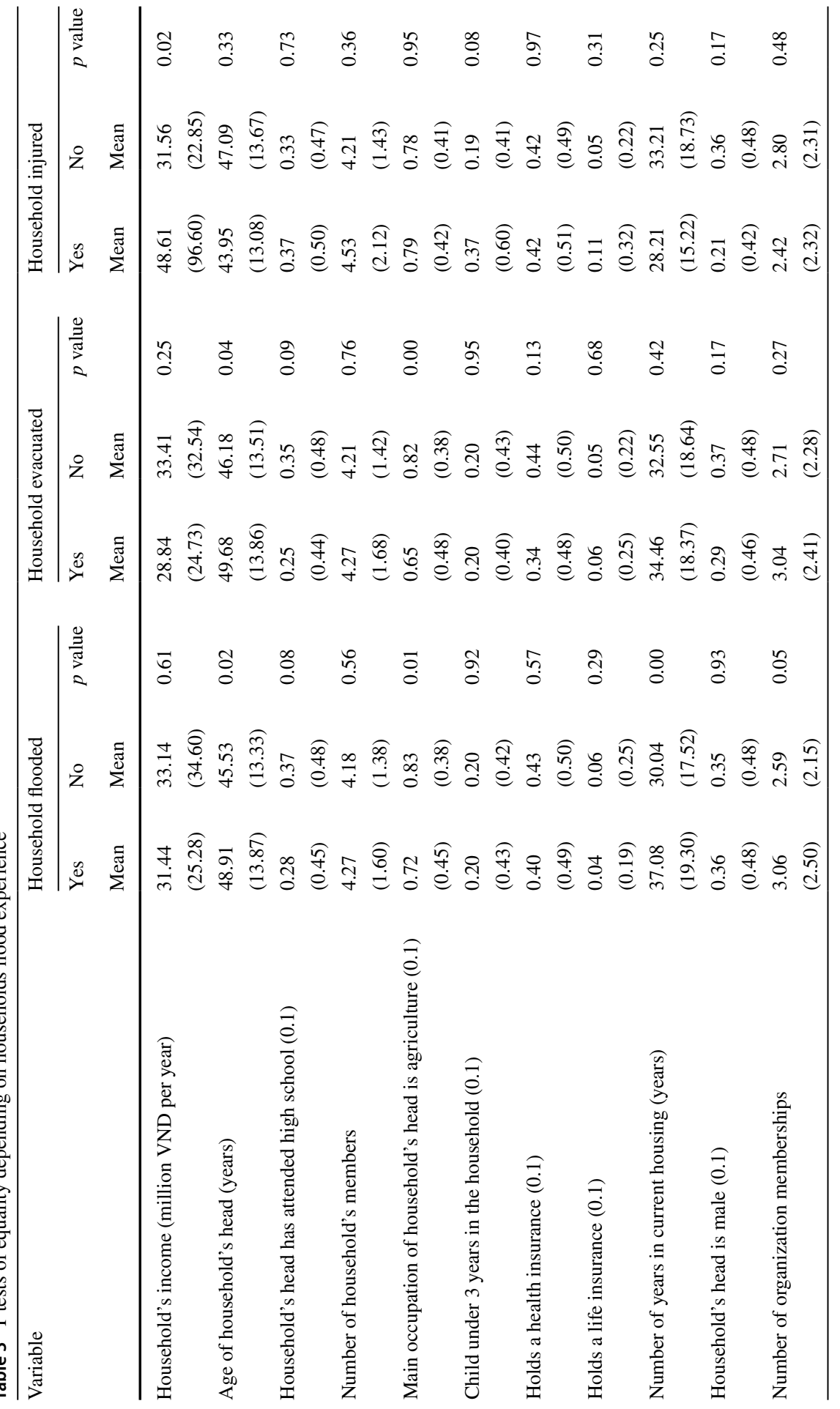

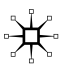




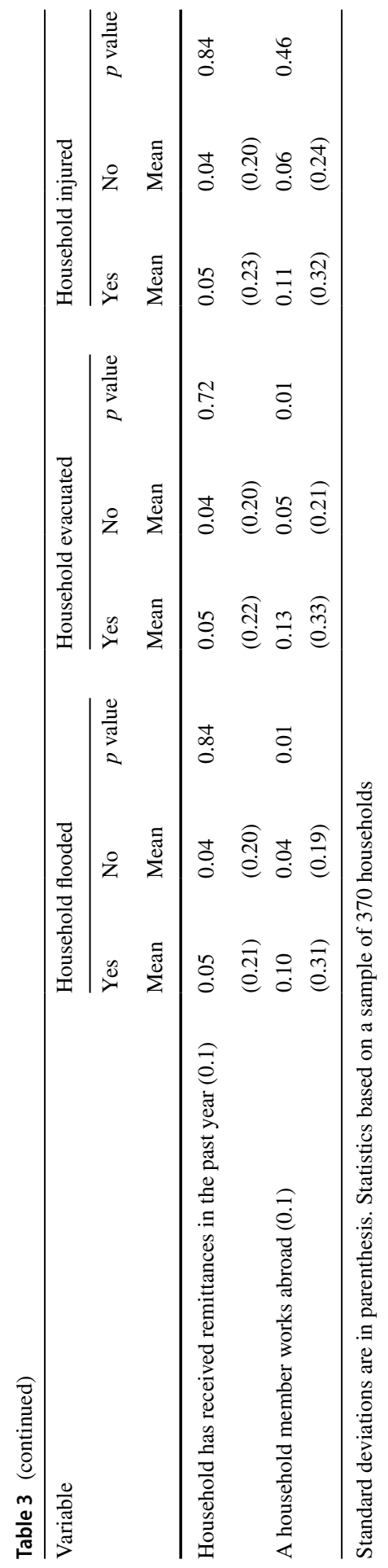


Table 4 Distribution of subjects per preferred lottery in the five risk tasks (in \%)

\begin{tabular}{|c|c|c|c|c|c|c|c|c|c|c|}
\hline & \multirow[t]{3}{*}{$N$} & \multicolumn{9}{|c|}{ Lottery number } \\
\hline & & \multicolumn{6}{|c|}{ Most risky } & \multicolumn{3}{|c|}{ Least risky } \\
\hline & & 1 & 2 & 3 & 4 & 5 & 6 & 7 & 8 & 9 \\
\hline \multicolumn{11}{|l|}{ Task 1 (gain) } \\
\hline All households & 370 & 20.8 & 11.6 & 13.5 & 10.0 & 12.7 & 7.3 & 8.7 & 5.7 & 9.7 \\
\hline Households with house flooded & 153 & 21.6 & 9.2 & 13.1 & 7.8 & 13.7 & 7.8 & 7.8 & 5.9 & 13.1 \\
\hline Households evacuated & 79 & 24.1 & 8.9 & 12.7 & 11.4 & 10.1 & 7.6 & 7.6 & 5.1 & 12.7 \\
\hline Households injured & 19 & 42.1 & 10.5 & 10.5 & 5.3 & 0.0 & 10.5 & 5.3 & 5.3 & 10.5 \\
\hline Flood elevation $\geq 100 \mathrm{~cm}$ & 33 & 18.2 & 6.1 & 6.1 & 12.1 & 18.2 & 12.1 & 3.0 & 9.1 & 15.2 \\
\hline Flood duration $\geq 8$ days & 65 & 23.1 & 9.2 & 16.9 & 6.2 & 9.2 & 7.7 & 7.7 & 3.1 & 16.9 \\
\hline \multicolumn{11}{|l|}{ Task 2 (gain) } \\
\hline All households & 370 & 15.7 & 24.9 & 16.0 & 7.6 & 4.9 & 6.0 & 8.9 & 4.9 & 11.4 \\
\hline Households with house flooded & 153 & 17.7 & 19.6 & 13.7 & 7.8 & 5.2 & 6.5 & 9.2 & 5.2 & 15.0 \\
\hline Households evacuated & 79 & 15.2 & 21.5 & 15.2 & 7.6 & 5.1 & 6.3 & 7.6 & 5.1 & 16.5 \\
\hline Households injured & 19 & 21.1 & 26.3 & 15.8 & 10.5 & 10.5 & 5.3 & 5.3 & 5.3 & 0.0 \\
\hline Flood elevation $\geq 100 \mathrm{~cm}$ & 33 & 21.2 & 9.1 & 12.1 & 9.1 & 3.0 & 3.0 & 12.1 & 6.1 & 24.2 \\
\hline Flood duration $\geq 8$ days & 65 & 18.5 & 21.5 & 18.5 & 6.2 & 6.2 & 4.6 & 1.5 & 6.2 & 16.9 \\
\hline \multicolumn{11}{|l|}{ Task 3 (gain) } \\
\hline All households & 370 & 18.7 & 14.1 & 14.6 & 14.3 & 13.8 & 9.7 & 3.8 & 8.1 & 3.0 \\
\hline Households with house flooded & 153 & 17.7 & 12.4 & 15.7 & 12.4 & 15.0 & 8.5 & 3.3 & 11.1 & 3.9 \\
\hline Households evacuated & 79 & 15.2 & 11.4 & 15.2 & 17.7 & 15.2 & 7.6 & 3.8 & 12.7 & 1.3 \\
\hline Households injured & 19 & 15.8 & 15.8 & 10.5 & 15.8 & 21.1 & 10.5 & 0.0 & 0.0 & 10.5 \\
\hline Flood elevation $\geq 100 \mathrm{~cm}$ & 33 & 15.2 & 6.1 & 12.1 & 15.2 & 18.2 & 9.1 & 6.1 & 15.2 & 3.0 \\
\hline Flood duration $\geq 8$ days & 65 & 15.4 & 10.8 & 13.9 & 12.3 & 20.0 & 4.6 & 6.2 & 12.3 & 4.6 \\
\hline \multicolumn{11}{|l|}{ Task 4 (loss) } \\
\hline All households & 370 & 15.1 & 17.8 & 21.1 & 23.8 & 22.2 & & & & \\
\hline Households with house flooded & 153 & 14.4 & 16.3 & 19.0 & 22.2 & 28.1 & & & & \\
\hline Households evacuated & 79 & 11.4 & 13.9 & 19.0 & 26.6 & 29.1 & & & & \\
\hline Households injured & 19 & 5.3 & 31.6 & 10.5 & 31.6 & 21.1 & & & & \\
\hline Flood elevation $\geq 100 \mathrm{~cm}$ & 33 & 15.2 & 9.1 & 21.2 & 39.4 & 15.2 & & & & \\
\hline Flood duration $\geq 8$ days & 65 & 15.1 & 17.8 & 21.1 & 23.8 & 22.2 & & & & \\
\hline \multicolumn{11}{|l|}{ Task 5 (loss) } \\
\hline All households & 370 & 11.9 & 22.4 & 24.1 & 16.2 & 25.4 & & & & \\
\hline Households with house flooded & 153 & 11.8 & 17.7 & 26.8 & 12.4 & 31.4 & & & & \\
\hline Households evacuated & 79 & 6.3 & 13.9 & 25.3 & 16.5 & 38.0 & & & & \\
\hline Households injured & 19 & 0.0 & 10.5 & 36.8 & 10.5 & 42.1 & & & & \\
\hline Flood elevation $\geq 100 \mathrm{~cm}$ & 33 & 15.2 & 15.2 & 18.2 & 21.2 & 30.3 & & & & \\
\hline Flood duration $\geq 8$ days & 65 & 12.3 & 12.3 & 30.8 & 15.4 & 29.2 & & & & \\
\hline
\end{tabular}

$N$ is the sample size. All households corresponds to the full sample. Households with house flooded, Households evacuated and Households injured respectively correspond to households whose house has been flooded at least once in the last 5 years, to households who have been evacuated at least once from their home in the last 5 years and to households who have suffered from at least one injury in the last 5 years. Flood elevation $\geq 100 \mathrm{~cm}$ is the subsample of households reporting a water elevation in their house greater than $100 \mathrm{~cm}$ at least once in the last 5 years and Flood duration $\geq 8$ days corresponds to households reporting that their house has been flooded more than 8 days per year on average in the last 5 years. All figures are percentages. For instance, in Task 1, 20.8\% of the respondents ( 370 households) declare to prefer lottery 1 . If we restrict the sample to households reporting that their house has been flooded at least once in the last 5 years (153 households), this percentage increases slightly to $21.6 \%$ 
and $42.1 \%$ of households who have been evacuated at least once in the last the last five years prefer the riskiest lottery (lottery 1) in comparaison to $20.8 \%$ for the full sample. In the loss domain (task 4 and task 5), households having experienced a flood, are on contrary more likely to prefer the safest lottery (lottery 5). This is especially true is task 5 where the proportion of household who prefer the safest lottery varies from $30.3 \%$ for household reporting that their house has been flooded more than 8 days per year on average in the last 5 years to $42.1 \%$ to households who have suffered from at least one injury in the last 5 years, whereas the percentage is only $25.4 \%$ on the full sample.

Table 5 presents the results of discrete choice models where the dependent variable is a dummy variable equal to 1 if an individual selects one of the two least risky, 'safest', lotteries (lotteries 8 and 9) in the tasks with gains, or the least risky lottery (lottery 5) in the tasks with losses. ${ }^{9}$ Each subject participated in five tasks. We, therefore, use panel estimation with unobserved individual effects that are modeled using a random-effects specification. Errors are clustered at the village level to account for possible intra-group correlation. Models (1), (2), (3), (4) and (5) correspond to different ways of measuring flood experience (respectively being flooded, evacuated, injured, more than 1 meter inside one's house, and a house flooded more than 8 days per year).

Our explanatory variables include socioeconomic characteristics of the household (age, gender, income, education), a dummy variable for tasks in the loss domain, a variable measuring a household's expectation about future flood damage and a variable measuring household participation to social and informal networks.

Respondents were asked to rank the flood damage they expect for their household in the next 10 years, on a scale going from 1 (no losses and no damage) to 10 (critical damage and losses). We argue that this variable provides a valid measure of personal flood risk perception, which is known to be an important determinant of decision-making under risk (Gollier and Pratt 1996; Quiggin 2003).

Informal and social networks play an important risk-sharing role in many developing countries and help households smooth their consumption despite potentially large income shocks. In a seminal paper, Townsend (1994) shows that communitybased informal insurance arrangements are very effective at smoothing poor Indian farmers' consumption over idiosyncratic income shocks. We thus include these networks as a potential determinant of decision-making under risk. Measuring social network participation at the household level is challenging, however, due to a high level of heterogeneity. We use as a proxy the number of institutions/organisations each household belongs to. Each respondent selected the organizations to whom he belonged within a list of twenty (including the Communist Party, religious groups, labor unions, professional associations, veteran associations) to which he could add a name if needed. The intensity of social connections is captured by the number of institutions/organisations each household belongs to (on average 2.7). While $14.51 \%$

\footnotetext{
9 As a robustness test we have also considered a dummy variable equal to 1 only if an individual selects the safest lottery in the gain domain. Econometric results are consistent with the ones reported in Table 5.
} 


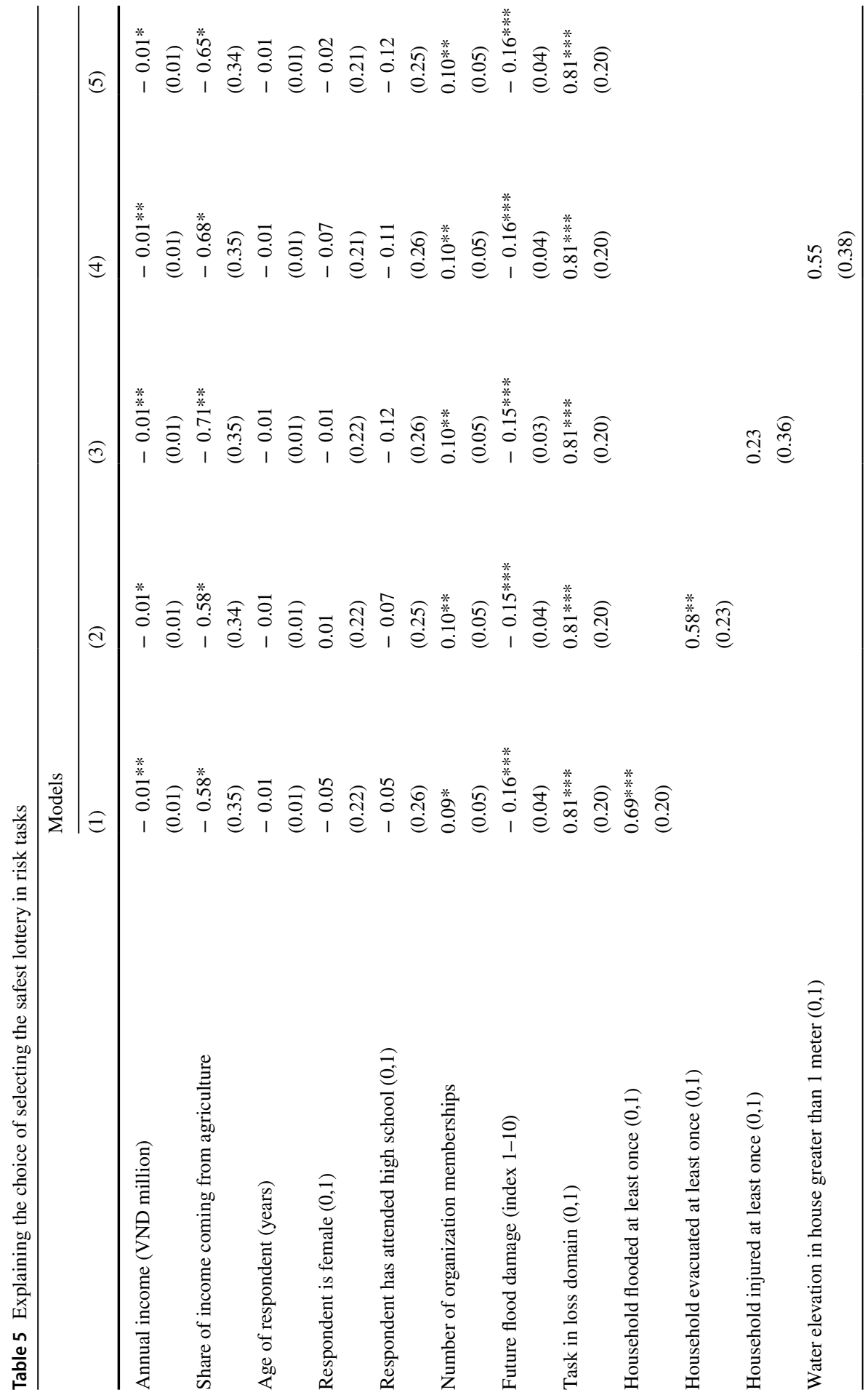

站。 


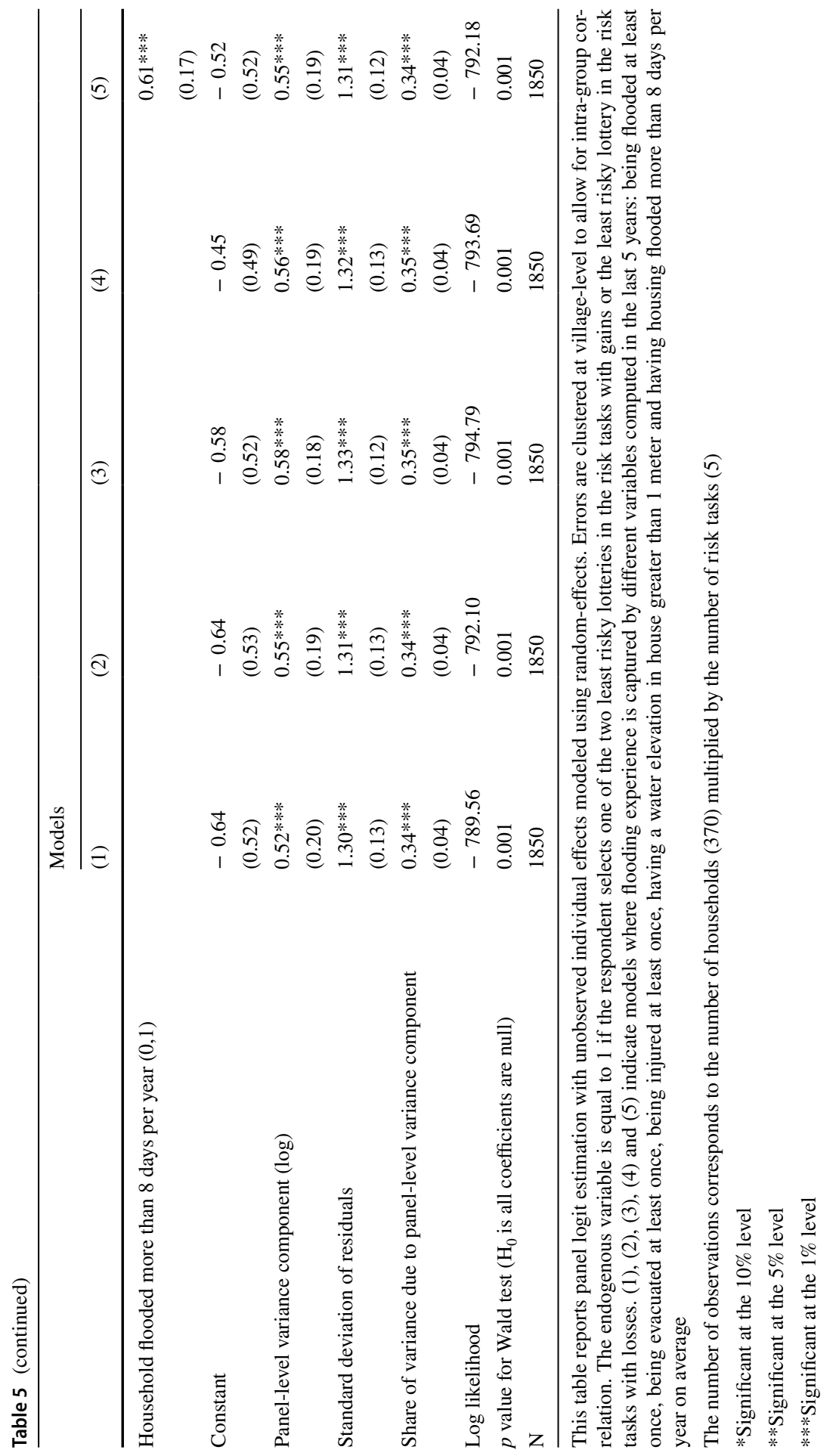


of households don't belong to any organization, $15.85 \%$ report a high level of social interactions (at least 5 different organizations).

Several results from Table 5 deserve attention.

(i) Flood experience is a strong predictor of choosing the safest lotteries. All coefficients of variables measuring flood experience are positive. Being flooded is significant at $1 \%$, being evacuated at $5 \%$. The intensity of flooding also matters since the likelihood of choosing the safest lotteries increases with the average duration of floods at $1 \%$ (flood elevation is close to being significant at $10 \%$, but is not). These preliminary results suggest that behaviors in lottery tasks are affected by individual flood experience.

(ii) Interestingly, households exhibit significantly different behavior in the loss and gain domains. We find that households are much more likely to select the safest lotteries in the loss domain than in the gain domain. The coefficient for the dummy variable used to identify the loss domain is positive and significant at $1 \%$ for all the models considered. This result confirms the need to consider different parameters in these two domains.

(iii) Our measure of expectations about future flood damage has a significant and negative coefficient: Respondents who expect a high future flood damage have a lower likelihood of selecting the safest lotteries. An interesting interpretation is that expectations may measure perceptions of a background risk. A background risk is an exogeneous risk that is uncorrelated with the main risk consideredin our case the lotteries (Eeckhoudt et al. 1996). Within an EU framework and under some assumptions, Gollier and Pratt (1996) have shown that an increase in background risk leads to more risk aversion, in contradiction with our finding. Conversely, for non-expected utility behaviors, Quiggin (2003) shows that with probability weighting, adding more background risk can actually increase the propensity of a decision-maker to select riskier choices-as in our sample. And for PT preferences, Beaud and Willinger (2015) show that a higher background risk can lead either to more or less risk-taking.

(iv) Household income is highly significant in all the models considered. Respondents with a high income are less likely to select the safest lotteries, so (absolute) risk aversion seems to be decreasing in wealth—as for farmers in China (Liu 2013) or Ethiopia (Yesuf and Bluffstone 2009); This is in line with our assumption of DARA (decreasing absolute risk aversion) preferences, that is implied by the use of a power function. ${ }^{10}$ The type of professional occupation also matters. Strong dependance on agricultural activities is associated with riskier choices-possibly due to self-selection into a riskier activity, or increasing risk tolerance due to contextual effects. Conversely, the individual characteristics of the respondent (age, gender, education) appear not to be significant. For comparison, Tanaka et al. (2010) report that gender (as here), ethnicity and income (contrary to here)

\footnotetext{
${ }^{10}$ Recall that with our specification the coefficient of absolute risk aversion are $(1-\alpha) / y$ in the gain domain and $(1-\beta) / y$ in the loss domain. They should thus be decreasing in income $y$, which is what we observe in our estimates.
} 
were non-significant in explaining risk preferences for a sample of Vietnamese households.

(v) Households with a large social network are also more likely to select the safest lotteries. Informal networks play an important risk diversification role in developing countries. Belonging to large networks provides insurance so that we would expect it to be associated to more risk taking. However, two other effects can explain why belonging to large networks and taking less risk correlates. First, households who wish to belong to several networks may be more risk-averse than others: They are willing to bear the costs of developing informal networks to get additional insurance, and they are likely to search for diversification in their social connections. Both elements indicate that they are probably more risk-averse. Second, individuals who are more risk-averse than others may find it easier to belong to large social networks: They can be viewed as 'safer' and more attractive connections, making it easier for them to match with others.

\subsection{Interval regressions of individual preference parameters}

Let us now consider some explanatory models for the three parameters $(\alpha, \beta$ and $\gamma)$ that describe risk preferences according to our PT specification. The dependent variables are the intervals for $\alpha, \beta$ and $\gamma$ that subjects implicitly choose when they select their preferred lotteries in the five risk tasks. All models are thus estimated using regressions with interval censoring (interval regression). Errors are clustered at the village level to account for possible intra-group correlation. ${ }^{11}$

Table 6 first presents estimates assuming homogenous risk preferences across individuals. In the second part of this table we introduce different measures of flood experience while, in the last part, we control for individual characteristics.

In the homogenous preference model presented in panel A, the coefficients for the curvature of the utility function are positive and significant in both the gain and the loss domains: the utility function is concave for gains and convex for losses, with a $S$-shape function, in line with the so-called reflection effect observed in the literature. Curvature coefficients are lower than one, reflecting a diminishing sensitivity to changes away from the reference point, taken to be zero. Last, the probability function exhibits the usual inverse-S shape, with a coefficient larger than one.

More importantly, we find that Vietnamese households appear to have domainspecific risk preferences. Indeed, the coefficient measuring utility curvature in the gain domain is significantly greater than the one for the loss domain ( $p<0.0001)$ : A given payoff change will result in a greater utility change in the gain domain than in the loss domain.

This is in contrast to estimates obtained with power functions in the literature for richer countries (and absent shocks): The latter tend to be slightly larger in the loss domain, but relatively similar (Booij et al. 2010). Compared to this literature, one

\footnotetext{
11 Interval regressions have also been estimated by including district-level fixed effects to account for regional heterogeneity. Results concerning the relationship between flood experience and risk preferences are qualitatively very similar to the ones presented in Table 6.
} 


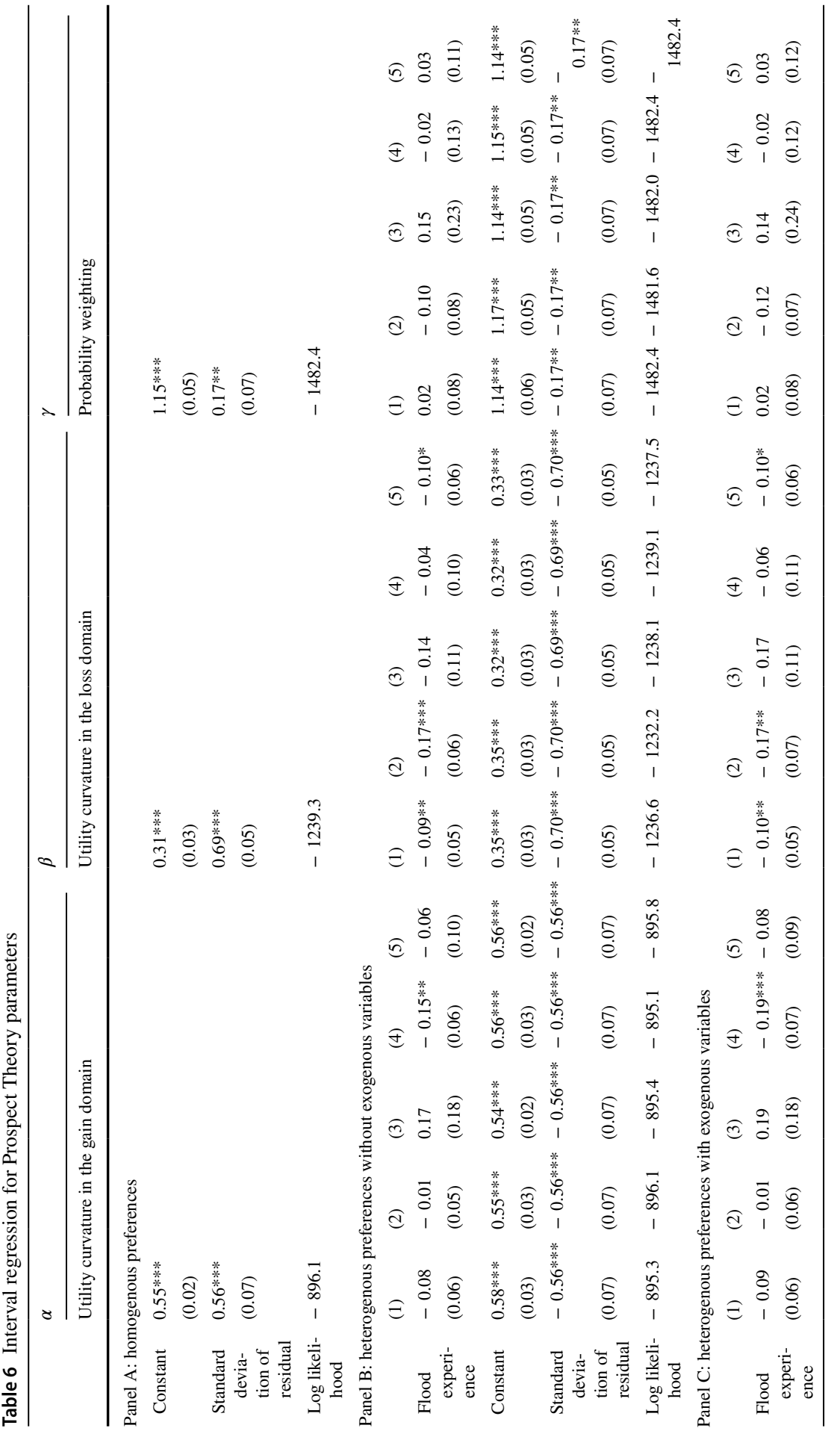

s.t. 


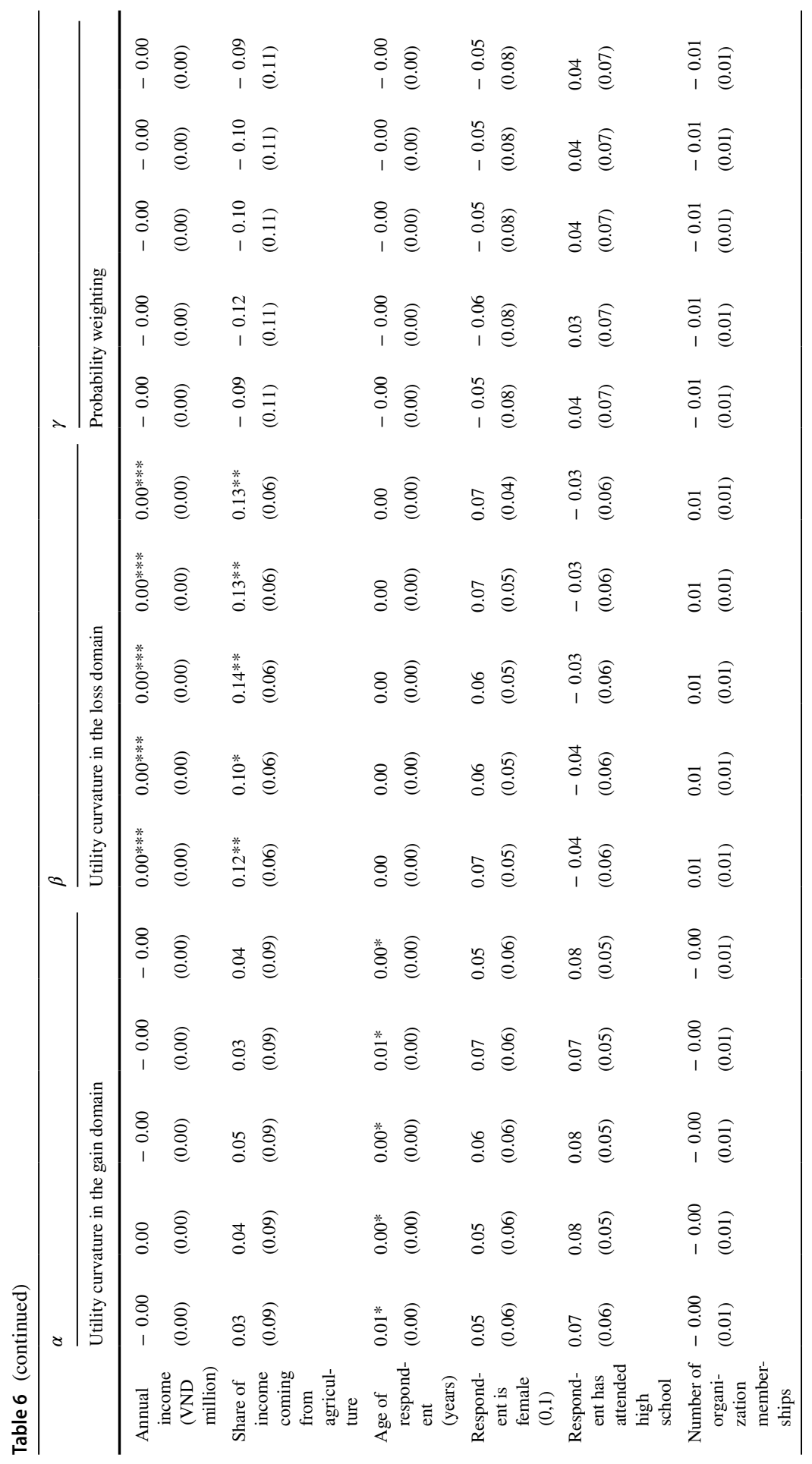




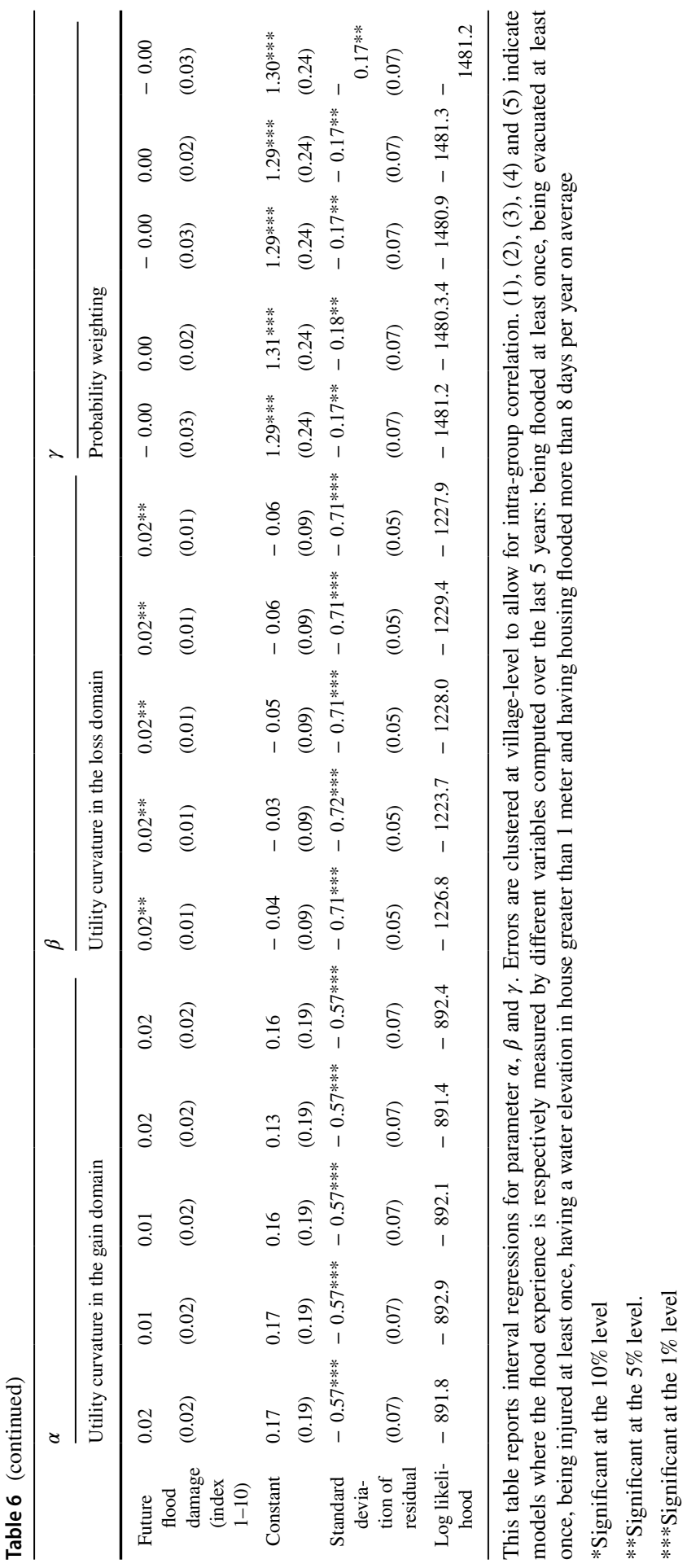

- 叙。 
can also note that the curvature coefficients are smaller (i.e., farther away from linearity) in our Vietnamese sample.

Domain-specific risk preferences imply that Vietnamese households may adopt different behaviors in the gain and in the loss domains. Those different behaviors would have not been captured by an EU model with a single risk aversion parameter. In what follows, we analyze whether flood experience has a uniform impact on risk preferences in both domains or, to the contrary, a differentiated impact.

The third column of panel A provides some evidence of probability distortions. Coefficient $\gamma$ is significantly different from one $(p<0.0001)$ : respondents do not use linear probability weighting in risk tasks. The probability weight estimates is 1.15 : respondents underestimate low probabilities and overestimates high probabilities. This S-shape of the probability weighting function is unusual in richer countries. However, Tanaka et al. (2010) and Liu (2013) obtain a similar pattern on a sample of Vietnamese households and Chinese farmers respectively. This result suggests policy implications: Launching education campaigns to raise public awareness about floods and their frequency may be effective in fostering preparation and prevention in Vietnam. Using taxes and subsidies may not be as effective, because the distortions in probabilities will affect decisions.

Panel B relates to the heterogeneous risk preference model in which the three parameters $\alpha, \beta$ and $\gamma$, are only impacted by flood experience.

(i) First, flood experience significantly shapes the utility function in the loss domain. Being flooded, being evacuated and a duration longer than 8 days are all significant, at 5,1 and 10\% respectively. These types of flood experience are associated with more risk aversion (the estimated coefficients of these three variables are negative).

(ii) Second, no significant impact is found in the gain domain, except for water elevation.

(iii) Third, we find no impact of flood experience on probability weighting. Vietnamese households underestimate low probabilities and overestimate high probabilities, but these distortions are unrelated to flood experience.

The estimates of the heterogeneous risk preference model controlling for individual characteristics, are consistent with the findings above. Risk preferences in the gain domain are almost not affected by flood experience. Only households reporting a maximal water elevation in their house greater than $100 \mathrm{~cm}$ at least once in the last 5 years appear to be more risk-averse in the gain domain. Risk preferences in the loss domain are much more impacted since being flooded or evacuated, or flooded for at least 8 days per year on average are significant. Flooded households tend to be more risk-averse in the loss domain. Only a few characteristics of respondents are significant for explaining utility curvature. Older respondents appear to be less riskaverse in the gain domain - an unusual result in richer countries (von Gaudecker et al. 2011; Dohmen et al. 2012)_but no significant impact is found in the loss domain. Households engaged in agricultural activities - that are inherently riskyare also less risk-averse; as mentioned, this is possibly due to habituation or to selfselection into those activities. It should be noted that income has a null coefficient 
(which is significant in the loss domain). This indicates that the curvature of the utility function both in the gain and loss domains is constant with respect to wealth. Our estimated preferences thus exhibit CRRA (as assumed in our specification of preferences). Lastly, probability weighting is not affected by any of the respondent's characteristics, which suggests highly homogenous preferences with respect to this parameter.

\section{Complementary analyses and robustness}

\subsection{Income and wealth effects}

Instead of representing preference changes, the behavioral differences we observe might be driven by the changes in income that accompany natural disasters: households may become more risk-averse after a flood simply because their relative wealth decreases. This explanation has been previously mentioned in the context of floods. For example, Cameron and Shah (2015) show that one part of the higher levels of risk aversion for individuals that suffered a flood or earthquake in Indonesia can be attributed to the effect of the incurred loss in income (under the assumption of a decreasing absolute risk aversion utility function).

Addressing empirically this issue is difficult in our context since we do not have in our data income or wealth before and after flood occurrence. However, our survey asked if floods have represented significant expenditures for their household over the previous 5 years. This question allows us to make a distinction between two categories of households impacted by a flood: those who have experienced significant income losses, and those who have not. As a robustness check, we have reestimated our models by interacting the flood experience variables ("being flooded" and "being evacuated") with dummy variables for individual reporting significant or insignificant expenditures due to flooding. ${ }^{12}$ Empirical results are presented in Table 7. Estimations must be interpreted with respect to the reference category (households not flooded in the last 5 years).

Results: Table 7 allows checking if bearing significant expenditures after a flood has an impact on parameters $\alpha, \beta$ and $\gamma$. The bottom of the table reports the result of the hypothesis test: "Flood experience $\times$ No significant expenditures" $=$ "Flood experience $\times$ Significant expenditures". In all cases except one the hypothesis of equal coefficients is not rejected. The observed changes in risk preferences in our data do not seem driven by wealth or income shocks after a flood.

\footnotetext{
12 The three other flood experiences (being injured, water elevation in house greater than $100 \mathrm{~cm}$ and being flooded more than 8 days per year) cannot be included due to high collinearity with reporting significant expenditures.
} 


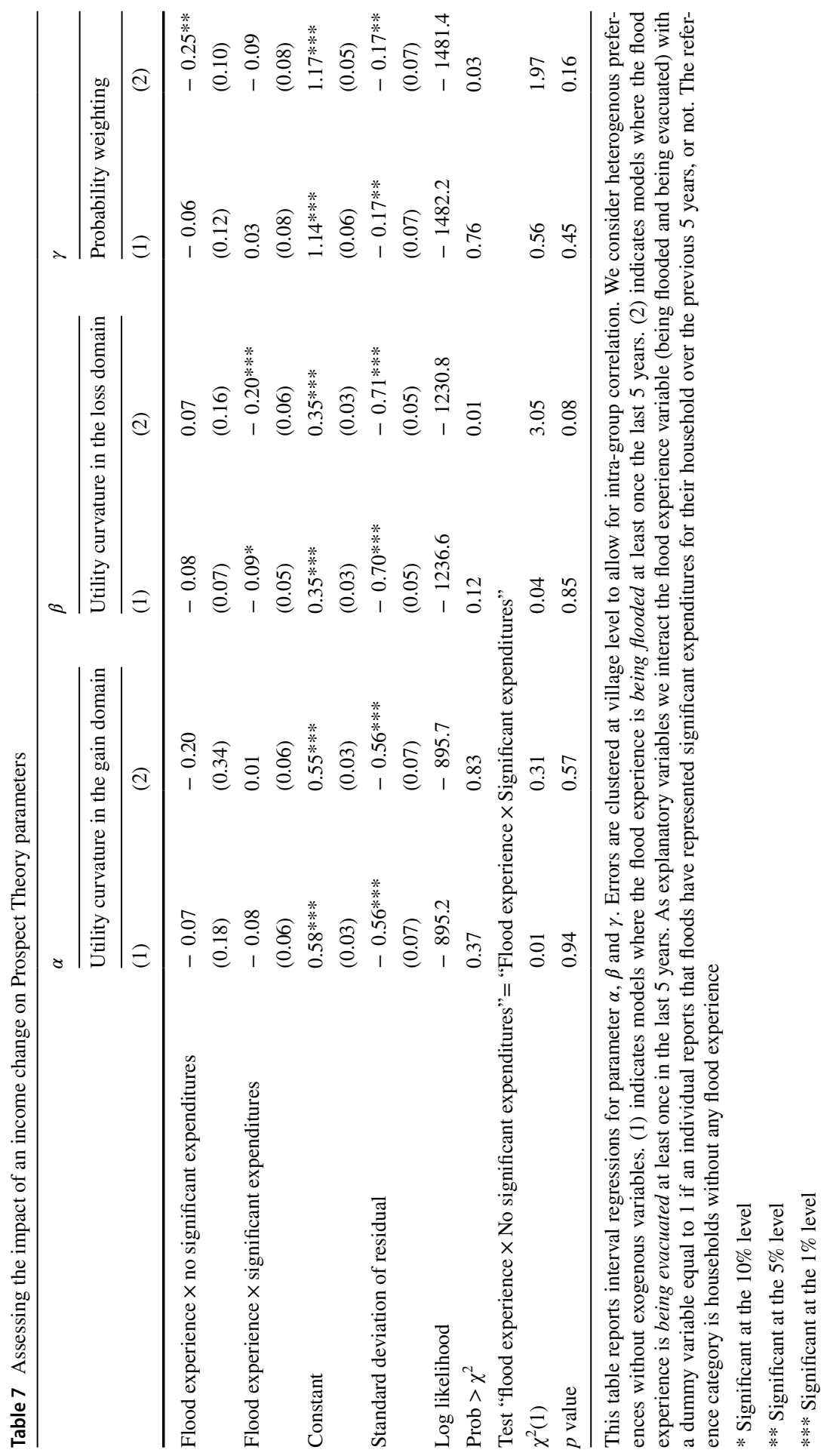




\subsection{Background risk}

The risk of a flood is only partly insurable at best, and can be considered exogenous at the time the subjects make decisions on the monetary lotteries. Flood risk, therefore, constitutes a "background risk" in the sense of Eeckhoudt et al. (1996): Flood risks are indeed risks "that are not under the control of the agent, and that are independent of endogenous risks", where the endogenous risks are the lotteries. A possible explanation for a change in financial risk taking after experiencing a flood is that this experience could change the respondents' perception about the background risk (a flood in the future). Such learning or updating could explain changes in risk attitudes even if risk preferences are actually not altered.

A household's expectation about future flood damage can be considered as a proxy for beliefs about the background risk. Our results, therefore, show that respondents who expect a high future flood damage (high background risk) are less likely to select the safest lotteries.

We consider below an alternative measure of the background risk. Cameron and Shah (2015) use the village mean number of earthquakes and floods as a proxy for background risk. Following them, we re-estimate our models, replacing the individual flood experience measures by village-level averages. Village-level mean flood exposure provides an alternative measure of background risk. We posit that the occurrence of a flood in the village induces a change in the perception of the background risk, and use mean exposure (an objective measure) as a proxy for this (subjective) perception. Aside from testing for robustness, there are two main reasons justifying to replace individual flood experience variables by village-level averages. First, reported individual flood experience measures may be strategically altered if respondents believed that the survey could be used by policy-makers. Second, the risk behavior of an individual who has not been directly affected by a flood in the past 5 years could still be modified if a large proportion of his neighbors has been affected. Interestingly, witnessing the effects of a flood on neighbors is likely to bring a similar informative content but a lower emotional upheaval than direct personal experience.

Flood risk perception is influenced by early disaster experiences, but other factors including socio-demographic characteristics, knowledge about hazards, institution trust, or feelings and emotions also play an important role (Bubeck et al. 2012). For this reason, we believe that background risk perception cannot be fully assessed through past disaster experience, and that our measure of subjective expectations about future flood damage is more relevant. Subjective expectation better incorporates these other factors, which is why we have favored it in the previous sections.

Results: We find that the village-level measure of background risk has an impact neither on the curvature of the utility function in the gain domain, nor on the probability weighting parameter, see Table $8 .{ }^{13}$

\footnotetext{
13 In Table 8, flood experience is measured by the fact that a household has been flooded at least once in the last 5 years. Results for being evacuated or injured are available from the authors upon request.
} 


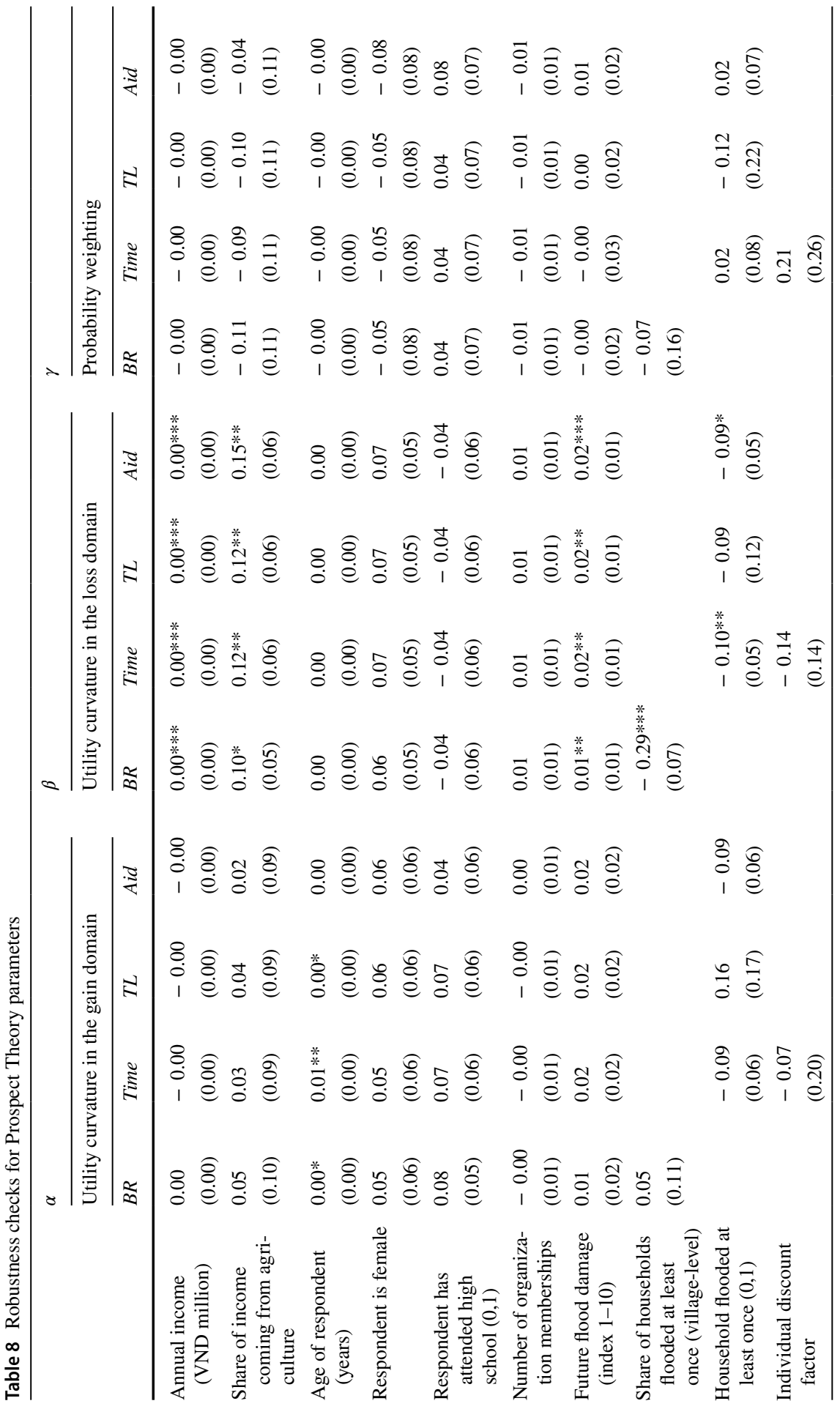




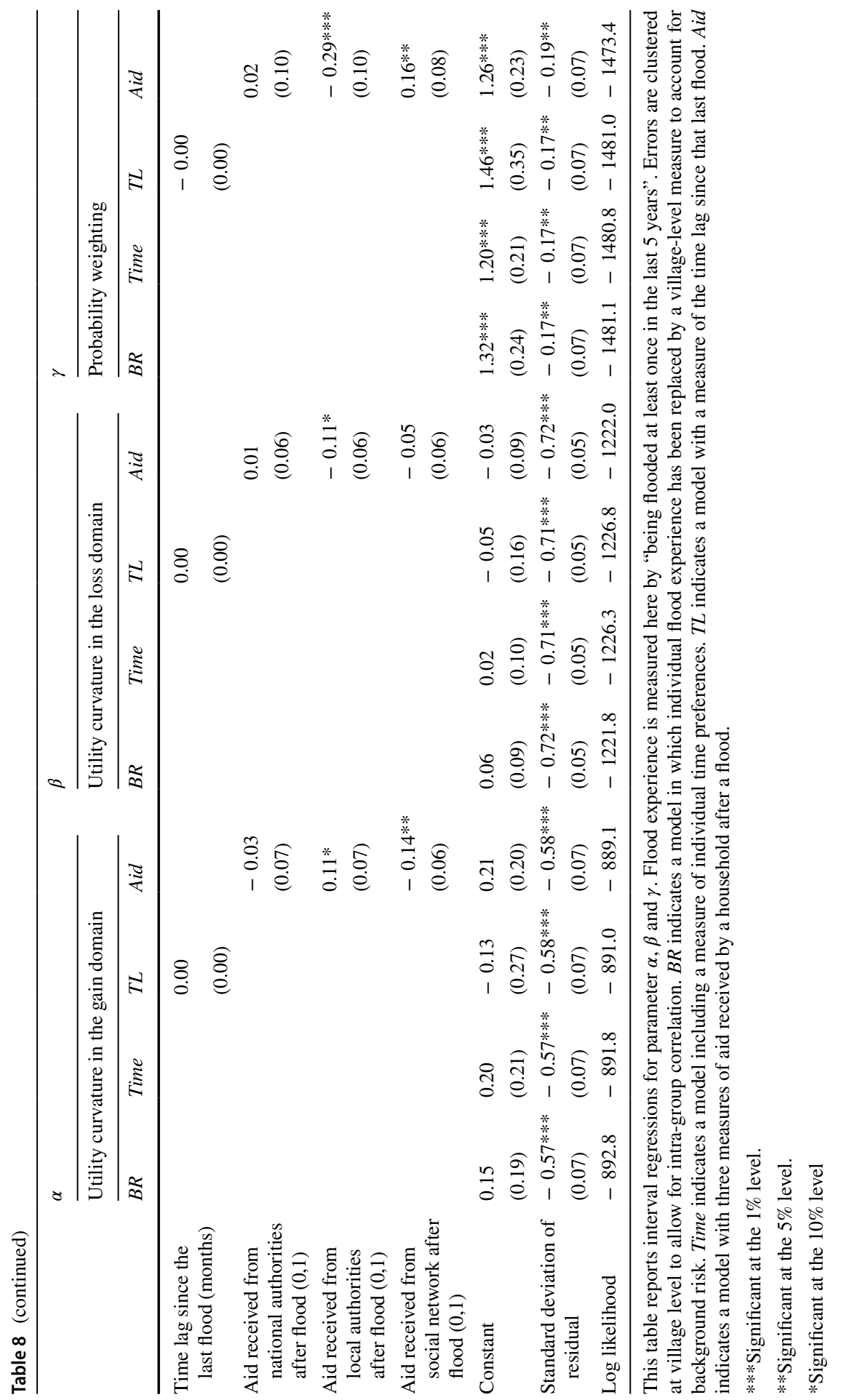

然 
We find, however, a significant and negative impact on the curvature of the utility function in the loss domain: a higher village-level background risk negatively impacts the curvature of the utility function in the loss domain (the estimate, -0.29 , is significant at the $1 \%$ level). It has no significant impact in the gain domain nor on probability weighting. This result strongly differs from the one we obtain with our individual, expectations-based measure. A possible explanation is that the villagelevel variable does not involve the same emotional impact as personal experience, and may not change beliefs in the same way. The village measure would thus imperfectly correlate with the change in risk perception. None of the variables which were significant with the individual measure of background risk is impacted by the inclusion of the village-level measure.

\subsection{Time preferences}

A potential concern is that we do not control for time preferences, whereas risk and time preferences might be correlated within individuals (Andersen et al. 2008). Because what an individual discounts is his utility from monetary amounts, and not the monetary amounts themselves, estimating risk aversion (to get the curvature of the utility function) is needed to precisely estimate discount rates. The discount rates can otherwise be overestimated. If they are indeed correlated, our risk aversion results could be biased due to the omission of individual time preferences (Cameron and Shah 2015). We thus include in the regressions individual discount factors elicited through hypothetical questions using a double referendum format (Supplementary Material 2).

Results: The discount factor is never significant in the regressions, see Table 8. Moreover, our main results about risk aversion are unchanged. The omission of time preferences therefore appears unproblematic.

\subsection{Temporary versus permanent change in preferences}

The persistence of the impact of natural disasters on risk preferences is not well known. Eckel et al. (2009) report that changes in risk preferences appear to attenuate within one year. Conversely Cameron and Shah (2015) and Callen (2015) document effects, respectively, up to two and a half years, and 9 years after exposure. Cassar et al. (2017) report that preferences in Thailand are significantly different for the respondents who lived in areas hit the hardest by the 2004 tsunami, four and a half years later.

Our data includes the month and year of the last occurence for each type of flood experience (being flooded, evacuated or injured). This provides measures of the time lag since the flood event. The average time lags are very similar for the three flood experience: a year and a month for being injured, a year and two months for being 
flooded or evacuated. We, therefore, retained only the time lag for being flooded in our estimates. Since the Nghe An Province has been affected by particularly strong flood episodes in 2011, the time lag is smaller than 12 months for $76.8 \%$ of flooded households; $8.6 \%$ of flooded households report, however, a time lag greater than 24 months.

Results: Table 8 shows that the time lag is never significant in our estimated models. This suggests that the shift in risk preferences after a flood persists over time, without significant attenuation over the relevant time period.

\subsection{Aid received by households after a disaster}

Some households having experienced a flood may have received some form of aid (either formal or informal) whereas other may not. This may create a problem for two reasons. Receiving aid might create an income effect which is not necessarily included into income data reported by respondents. Receiving aid may also alter individual preferences for risk, as it does for trust and generosity. Receiving aid indeed makes people more trusting in the long run (Andrabi and Das 2010; Cameron and Shah 2015) and increases generosity, but only for the most affected individuals, after a tsunami in Sri Lanka (Becchetti et al. 2017).

To address these issues, we asked each household if he received any form of aid (financial or material) after having experienced a flood. Aid from local authorities is reported by $62.97 \%$ of households. Respectively $47.02 \%$ and $48.35 \%$ report aid from national authorities and from social networks (family, friends, neighbors, community associations and NGOs). Vietnamese local authorities are indeed in charge of relief distribution to flood victims.

Results: We find that receiving aid from local authorities or from social networks has a significant impact on risk preferences. Households having received aid from social networks appear to be more risk-averse in the gain domain. This may be because receiving aid from social networks implies reciprocity, including sharing large future windfalls, which makes more average gains more attractive. Risk aversion also increases for aid received from local authorities, but in the loss domain. ${ }^{14}$

We also find that receiving aid after a flood significantly shapes probability weighting. Interestingly, the impact depends upon the aid provider. Households who received aid from local authorities distort probabilities in a very limited way, whereas the S-shape of the probability weighting function is exacerbated for households benefitting from aid from social networks. This impact may have to do with the perception of households about their ability to face adverse events. Besides, aid from local authorities and from social networks differ in two important dimensions: First, local authorities intervene in case of a flood but not in case of private adverse events, contrary to social networks; Second, aid from local authorities does not impose significant costs, contrary to aid from social networks. The latter entails

\footnotetext{
14 A tentative explanation is that formal aid tends to consists in fixed transfers (at least in a given range of flood severity) so that it covers well average losses but is not responsive to very large losses. This aspect of formal aid would be more salient to those households who experienced it.
} 
reciprocity, reimbursement and providing for less favored members when one benefits from 'good times', as mentioned above. Social networks thus insure households, by attenuating both large losses and large gains, under reciprocal solidarity. This insurance property may make exceptional events less important. This would correspond to the exacerbated S-shape that we observe for probability weighting.

\section{Conclusion}

\subsection{Academic implications}

We have shown that the preferences of respondents are best described by PT (rather than EU) and are in line with the assumptions of DARA and CRRA. Importantly for our object of study, experience with being flooded or evacuated significantly increases risk aversion in the loss domain. Flood experience has, however, no significant impact in the gain domain. This differential impact in the loss and gain domains may help explain why some works report a significant impact of natural disasters on risk preferences (Eckel et al. 2009; Andrabi and Das 2010; Li et al. 2011a; Cameron and Shah 2015; Cassar et al. 2017) while others do not (Voors et al. 2012; Callen 2015; Said et al. 2015). Because other studies do not distinguish estimates between gains and losses, they measure overall effects, and the number of tasks with gains or with losses varies across studies. This may explain the variance in results.

We also contribute to the empirical literature which assesses the impact of background risk perception on risk-taking behaviors. Our empirical analysis reveals that results drastically differ depending on the measure used for background risk. With the measure based on individual subjective expectations about future impacts of flood, a higher background risk is associated with more risk taking. We obtain an opposite result with a measure based on local (village) experience, a result in line with the risk vulnerability conjecture. Importantly, for both measures of background risk, flood experience retains its significance. This indicates that the impact of flood on preferences goes beyond a change in background risk perception.

Both results mentioned above suggest a possible role of emotions. Flooding is a highly emotional event. One possible explanation for the difference in the gain and loss domains is that emotions are more intensely triggered, and more durable, for losses than for gains (Levin et al. 2012; De Martino et al. 2010; Shin et al. 2006; Scott et al. 2015). The difference in the impact of personal subjective expectations and local, more objective, information could also arise from the stronger emotions triggered by personal experience than by external observation. Future research would be needed to confirm whether more intense emotional involvement is associated to stronger impacts on preferences. 


\subsection{Implications for policy and forecasting}

We find no impact of flood experience on probability weighting. Vietnamese households underestimate low probabilities and overestimate high probabilities, but interestingly, these distortions are unrelated to flood experience: Distortions do not seem to respond to learning from experience. Education and informational campaigns about flood risks could be quite valuable ways of fostering prevention despite behavioral biases in probability weighting. Other instruments that target only financial valuation (such as subsidies) may be less cost-effective, given these biases, even if they may present other benefits.

Our results also highlight that receiving aid makes individuals more risk-taking. Receiving aid also impacts the way individuals assess probabilities, but in a very different way depending on the source of aid: aid from local authorities limits probability distortions while aid from social networks, perhaps due to expected reciprocal contributions in good times, amplifies the S-shape of the probability weighting function. This is in contrast with the absence of impact of the disaster experience per se on probability weighting, suggesting that mechanisms unrelated to the disaster itself, possibly associated to social relations and expectations, come into play. Crowding out informal aid with highly subsidized public aid might lead to more objective weighing of events, with consequences on prevention.

Additionally, we observe no attenuation of the impact of floods when the time lag since the last occurrence increases, in the time range available in our data. Flooding may, therefore, have a lasting impact on choices made to deal with disaster risk (self-protection and insurance), through risk aversion if not through probability weighting. Because flood experience increases risk aversion in the loss domain, a sufficiently strong demand for disaster insurance should emerge over time. Self-protection efforts should also increase, ceteris paribus.

Acknowledgements We thank Mr. Nhung Nguyen from the Vietnamese Ministry of Agriculture and Rural Development for his patience when explaining flood protection in Vietnam. We also thank Thanh Duy Nguyen for his very efficient assistance during the field work and Maht Hung Nguyen for his work during the survey. The field survey would not have been possible without the support of the VanXuan University of Technology at Cua Lo. This research is funded by Vietnam National Foundation for Science and Technology Development (NAFOSTED) under grant number 502.01-2016.18. We acknowledge funding from ANR under grant ANR-17-EUR-0010 (Investissements d'Avenir program). Conflict of Interest: The authors declare that they have no conflict of interest.

\section{References}

Abdellaoui, M. 2000. Parameter-free elicitation of utility and probability weighting functions. Management Science 46 (11): 1385-1512.

Abdellaoui, M., H. Bleichrodt, and O. L'Haridon. 2008. A tractable method to measure utility and loss aversion under prospect theory. Journal of Risk and Uncertainty 36 (3): 245-266.

Abdellaoui, M., H. Bleichrodt, O. L'Haridon, and D. van Dolder. 2016. Measuring loss aversion under ambiguity: A method to make prospect theory completely observable. Journal of Risk and Uncertainty 52 (1): 1-20. 
Ali Bchir, M. and M. Willinger (2013). Does the exposure to natural hazards affect risk and time preferences? Some insights from a field experiment in Peru. LAMETA working paper serie 2013. University of Montpellier, France.

Andersen, S., G.W. Harrison, M.I. Lau, and E.E. Rutström. 2008. Lost in state space: Are preferences stable? International Economic Review 49 (3): 1091-1112.

Andrabi, T. and J. Das (2010). In aid we trust: Hearts and minds and the Pakistan earthquake of 2005. Policy Research Working Paper 5440, The World Bank.

Azevedo, C.D., J.A. Herriges, and C.L. Kling. 2003. Combining revealed and stated preferences: Consistency tests and their interpretations. American Journal of Agricultural Economics 85 (3): 525-537.

Baucells, M., and A. Villasís. 2010. Stability of risk preferences and the reflection effect of prospect theory. Theory and Decision 68 (1): 193-211.

Beaud, M., and M. Willinger. 2015. Are people risk vulnerable? Management Science 61 (3): 624-636.

Becchetti, L., S. Castriota, and P. Conzo. 2017. Disaster, aid, and preferences: The long-run impact of the tsunami on giving in sri lanka. World Development 94 (C): 157-173.

Binswanger, H.P. 1980. Attitudes toward risk: Experimental measurement in rural India. American Journal of Agricultural Economics 62 (3): 395-407.

Booij, A.S., B. van Praag, and G. van de Kuilen. 2010. A parametric analysis of prospect theory's functionals for the general population. Theory and Decision 68 (1-2): 115-148.

Bruhin, A., H. Fehr-Duda, and T. Epper. 2010. Risk and rationality: Uncovering heterogeneity in probability distortion. Econometrica 78 (4): 1375-1412.

Brunette, M., J. Foncel, and E.N. Kéré. 2017. Attitude towards risk and production decision: An empirical analysis on french private forest owners. Environmental Modeling and Assessment 22 (6): 563-576.

Bubeck, P., W.J.W. Botzen, and J.C.J.H. Aerts. 2012. A review of risk perceptions and other factors that influence flood mitigation behavior. Risk Analysis 32 (9): 1481-1495.

Callen, M. 2015. Catastrophes and time preference: Evidence from the Indian Ocean Earthquake. Journal of Economic Behavior \& Organization 118: 199-214.

Cameron, L., and M. Shah. 2015. Risk-taking behavior in the wake of natural disasters. Journal of Human Resources 50 (2): 484-515.

Cassar, A., A. Healy, and C. von Kessler. 2017. Trust, risk, and time preferences after a natural disaster: Experimental evidence from Thailand. World Development 94: 90-105.

Castillo, M., R. Petrie, and M. Torero. 2010. On the preferences of principals and agents. Economic Inquiry 48 (2): 266-273.

Chuang, Y., and L. Schechter. 2015. Stability of experimental and survey measures of risk, time, and social preferences: A review and some new results. Journal of Development Economics 117: 151-170.

Dang Nguyen, A. 2009. Household registration system and the well-beings of rural-to-urban migrants. Vietnam's Socio-economic Development: A Social Science Review 59 (9): 75-80.

Dave, C., C.C. Eckel, C.A. Johnson, and C. Rojas. 2010. Eliciting risk preferences: When is simple better? Journal of Risk \& Uncertainty 41 (3): 219-243.

De Martino, B., C.F. Camerer, and R. Adolphs. 2010. Amygdala damage eliminates monetary loss aversion. Proceedings of the National Academy of Sciences 107 (8): 3788-3792.

Dionne, G., and L. Eeckhoudt. 1985. Self-insurance, self-protection and increased risk aversion. Economics Letters 17 (1-2): 39-42.

Dohmen, T., A. Falk, D. Huffman, and U. Sunde. 2012. The intergenerational transmission of risk and trust attitudes. Review of Economic Studies 79 (2): 645-677.

Dohmen, T., A. Falk, D. Huffman, U. Sunde, J. Schupp, and G.G. Wagner. 2011. Individual risk attitudes: Measurement, determinants, and behavioral consequences. Journal of the European Economic Association 9 (3): 522-550.

Eckel, C.C., M.A. El-Gamal, and R.K. Wilson. 2009. Risk loving after the storm: A Bayesian-network study of Hurricane Katrina evacuees. Journal of Economic Behavior \& Organization 69 (2): 110-124.

Eckel, C.C., and P.J. Grossman. 2002. Sex differences and statistical stereotyping in attitudes toward financial risk. Evolution and Human Behavior 23 (4): 281-295.

Eckel, C.C., and P.J. Grossman. 2008. Forecasting risk attitudes: An experimental study using actual and forecast gamble choices. Journal of Economic Behavior \& Organization 68 (1): 1-7.

Eeckhoudt, L., C. Gollier, and H. Schlesinger. 1996. Changes in background risk and risk-taking behavior. Econometrica 64 (3): 683-89. 
Ehrlich, I., and G.S. Becker. 1972. Market insurance, self-insurance, and self-protection. Journal of Political Economy 80 (4): 623-648.

Engle-Warnick, J., J. Escobal, and S. Laszlo. 2009. How do additional alternatives affect individual choice under uncertainty? Canadian Journal of Economics 42 (1): 113-140.

Gollier, C., and J.W. Pratt. 1996. Risk vulnerability and the tempering effect of background risk. Econometrica 64 (5): 1109-1123.

Gonzalez, R., and G. Wu. 1999. On the shape of the probability weighting function. Cognitive Psychology 38 (1): 129-166.

Harrison, G.W., and E.E. Rutström. 2008. Risk aversion in the laboratory. Research in Experimental Economics 12: 41-196.

Hirabayashi, Y., R. Mahendran, S. Koirala, L.K.D. Yamazaki, S. Watanabe, H. Kim, and S. Kanaee. 2013. Global flood risk under climate change. Nature Climate Change 3: 816-821.

Ho, M.-C., D. Shaw, S. Lin, and Y.-C. Chiu. 2008. How do disaster characteristics influence risk perception? Risk Analysis 28 (3): 635-643.

Hopland, A.O., E. Matsen, and B. Strom. 2016. Income and choice under risk. Journal of Behavioral and Experimental Finance 12: 55-64.

Kahneman, D., and A. Tversky. 1979. Prospect theory: An analysis of decision under risk. Econometrica 47 (2): 263-291.

Kimball, M.S. 1993. Standard risk aversion. Econometrica 61 (3): 589-611.

Knuth, D., D. Kehl, L. Hulse, and S. Schmidt. 2014. Risk perception, experience, and objective risk: A cross-national study with European emergency survivors. Risk Analysis 34 (7): 1286-1298.

Levin, I.P., and S.S. Hart. 2003. Risk preferences in young children: Early evidence of individual differences in reaction to potential gains and losses. Journal of Behavioral Decision Making 16 (5): 397-413.

Levin, I.P., G. Xue, J.A. Weller, M. Reimann, M. Lauriola, and A. Bechara. 2012. A neuropsychological approach to understanding risk-taking for potential gains and losses. Frontiers in Neuroscience 6: 15.

Li, J.-Z., S. Li, and H. Liu. 2011. How has the Wenchuan earthquake influenced people's intertemporal choices? Journal of Applied Social Psychology 41 (11): 2739-2752.

Li, J.-Z., S. Li, W.-Z. Wang, L.-L. Rao, and H. Liu. 2011. Are people always more risk averse after disasters? Surveys after a heavy snow-hit and a major earthquake in China in 2008. Applied Cognitive Psychology 25 (1): 104-111.

Liu, E.M. 2013. Time to change what to sow: Risk preferences and technology adoption decisions of cotton farmers in China. Review of Economics and Statistics 95 (4): 1386-1403.

Loewenstein, G.F., E.U. Weber, C.K. Hsee, and N. Welch. 2001. Risk as feelings. Psychological Bulletin 127 (2): 267-286.

Mai, C.V., M.J. Stive, and P.H. VanGelder. 2009. Coastal protection strategies for the red river delta. Journal of Coastal Research 25 (1): 105-116.

Nguyen-Hoang, P., and J. McPeak. 2010. Leaving or staying: Inter-provincial migration in vietnam. Asia and Pacific Migration Journal 19 (4): 473-500.

Page, L., D.A. Savage, and B. Torgler. 2014. Variation in risk seeking behaviour following large losses: A natural experiment. European Economic Review 71: 121-131.

Pilarczyk, K.W., and N.S. Nuoi. 2005. Experience and practices on flood control in Vietnam. Water International 30 (1): 114-122.

Quiggin, J. 2003. Background risk in generalized expected utility theory. Economic Theory 22 (3): $607-611$.

Reynaud, A., C. Aubert, and M.-H. Nguyen. 2013. Living with floods: Protective behaviours and risk perception of Vietnamese households. Geneva Papers on Risk and Insurance Issues and Practice 38: 547-579.

Reynaud, A., and M.-H. Nguyen. 2016. Valuing flood risk reductions. Environmental Modeling \& Assessment 21 (5): 603-617.

Reynaud, A., M.-H. Nguyen, and C. Aubert. 2018. Is there a demand for flood insurance in Vietnam? Results from a choice experiment. Environmental Economics and Policy Studies 20 (3): 593-617.

Said, F., U. Afzal, and G. Turner. 2015. Risk taking and risk learning after a rare event: Evidence from a field experiment in Pakistan. Journal of Economic Behavior \& Organization 118: 167-183.

Samphantharak, K. and S. Chantarat (2015). The effects of natural disasters on households' preferences and behaviours: Evidence from thai farmers during and after the 2011 mega flood. Disaster Risks, 
Social Preferences, and Policy Effects: Field Experiments in Selected ASEAN and East Asian Coutries, 57-84.

Schoemaker, P. 1990. Are risk-attitudes related across domains and response modes? Management Science 36 (12): 1451-1463.

Scott, J.C., G.E. Matt, K.M. Wrocklage, C. Crnich, J. Jordan, S.M. Southwick, J.H. Krystal, and B.C. Schweinsburg. 2015. A quantitative meta-analysis of neurocognitive functioning in posttraumatic stress disorder. Psychological Bulletin 141 (1): 105.

Shin, L.M., S.L. Rauch, and R.K. Pitman. 2006. Amygdala, medial prefrontal cortex, and hippocampal function in ptsd. Annals of the New York Academy of Sciences 1071 (1): 67-79.

SwissRe, 2012. World insurance in 2011-non-life ready for take-off. Sigma 3: 1-40.

Tanaka, T., C. Camerer, and Q. Nguyen. 2010. Risk and time preferences: Linking experimental and household survey data from vietnam. American Economic Review 100 (1): 557-571.

Townsend, R.M. 1994. Risk and insurance in village India. Econometrica 62 (3): 539-591.

Tversky, A., and D. Kahneman. 1992. Advances in prospect theory: Cumulative representation of uncertainty. Journal of Risk and Uncertainty 5 (4): 297-323.

von Gaudecker, H.-M., A. van Soest, and E. Wengstrom. 2011. Heterogeneity in risky choice behavior in a broad population. American Economic Review 101 (2): 664-694.

Voors, M.J., E.E. Nillesen, P. Verwimp, E.H. Bulte, R. Lensink, and D.P. Van Soest. 2012. Violent conflict and behavior: A field experiment in Burundi. American Economic Review 102 (2): 941-964.

Weber, E. U. and J. S. Ancker (2010). Risk perceptions and risk attitudes in the United States and Europe. The Reality of Precaution: Comparing Approaches to Risk Regulation in the United States and Europe. J. B. Wiener, M. D. Rogers, P. H. Sand, and J. K. Hammitt (eds). Ch. 18, Taylor and Francis.

Weller, J.A., I.P. Levin, B. Shiv, and A. Bechara. 2007. Neural correlates of adaptive decision making for risky gains and losses. Psychological Science 18 (11): 958-964.

WorldBank (2005). Natural disaster hotspots: A global risk analysis. Disaster Risk Management Series No. 5, Hazard Management Unit, The World Bank.

WorldBank (2010). Weathering the Storm: Options for Disaster Risk Financing in Vietnam. The World Bank.

Yesuf, M., and R.A. Bluffstone. 2009. Poverty, risk aversion, and path dependence in low-income countries: Experimental evidence from Ethiopia. American Journal of Agricultural Economics 91 (4): 1022-1037. 